\title{
WestVirginiaUniversity
}

THE RESEARCH REPOSITORY @ WVU

Graduate Theses, Dissertations, and Problem Reports

2018

\section{What the Frost Killed}

Allison Semele Blair

Follow this and additional works at: https://researchrepository.wvu.edu/etd

\section{Recommended Citation}

Blair, Allison Semele, "What the Frost Killed" (2018). Graduate Theses, Dissertations, and Problem Reports. 5221.

https://researchrepository.wvu.edu/etd/5221

This Thesis is protected by copyright and/or related rights. It has been brought to you by the The Research Repository @ WVU with permission from the rights-holder(s). You are free to use this Thesis in any way that is permitted by the copyright and related rights legislation that applies to your use. For other uses you must obtain permission from the rights-holder(s) directly, unless additional rights are indicated by a Creative Commons license in the record and/ or on the work itself. This Thesis has been accepted for inclusion in WVU Graduate Theses, Dissertations, and Problem Reports collection by an authorized administrator of The Research Repository @ WVU. For more information, please contact researchrepository@mail.wvu.edu. 


\title{
What the Frost Killed
}

\section{Allison Semele Blair}

\author{
Thesis submitted \\ to the College of Creative Arts \\ at West Virginia University
}

in partial fulfillment of the requirements for the degree of Master of Fine Arts

in Printmaking

\author{
Joseph Lupo, MFA (chair) \\ Kristina Olson, MA \\ Michael Sherwin, MFA \\ Joseph Galbreath, MFA
}

School of Art and Design

\section{Morgantown, WV \\ 2018}
Keywords: Cyanotype, Printmaking, Photography, Tragedy Copyright: 2018 Allison Semele Blair




\section{Abstract \\ What the Frost Killed \\ Allison Semele Blair}

What the Frost Killed is the culmination of two years spent memorializing the dead plants and animals of my immediate surroundings. Primarily focusing on birds who die as a result of human activity, I seek to pay attention to and elevate the individual victims of a systemic problem. Inspired by Ancient Greek tragedy, I engage with the ethical dilemmas inherent in our collective actions to express the strange, beauty of these unsung deaths.

My thesis body of work draws on a decade of research exploring the intersection between political history and ancient tragic literature. As I studied these stories written in dead languages, I was perpetually struck by the way they seemed to speak to the present moment. Now, as I make my work, I express the relevance of the past to the present both in its content and the process of its creation. After encountering my dead subjects in my daily life, I digitize their image on a flatbed scanner, then reinterpret these images using the 19th century process of cyanotype, combining old and new techniques from the history of photography to create a specific aesthetic. The cyanotype medium lends a characteristic blue color, high contrast, and soft image quality that enhances the tragic mood of my prints, while digital manipulation allows me to render some of my work on a monumental scale.

What the Frost Killed, the titular piece, began as a project documenting what died in my garden the week of the 2016 election, which coincided with the first hard frost of the year. As November 2016 and the politically turbulent year that followed affected me profoundly, I view the exhibition as a whole to be a product of my response to the national climate. My thesis presents funerary images of birds and flowers, mourning for the victims of a terrible year. 


\section{Acknowledgements}

I would like to express my gratitude to all of my committee members, professors, and fellow graduate students. I would especially like to thank my partner, Michael McDevitt, for his support, assistance, and insights throughout my three years at West Virginia University. I am also grateful for the assistance of Feliks Pyron, Michael Oliver, Olivia Richardson, and Michael Parsons during the installation and disassembly of my thesis exhibition. 
Table of Contents

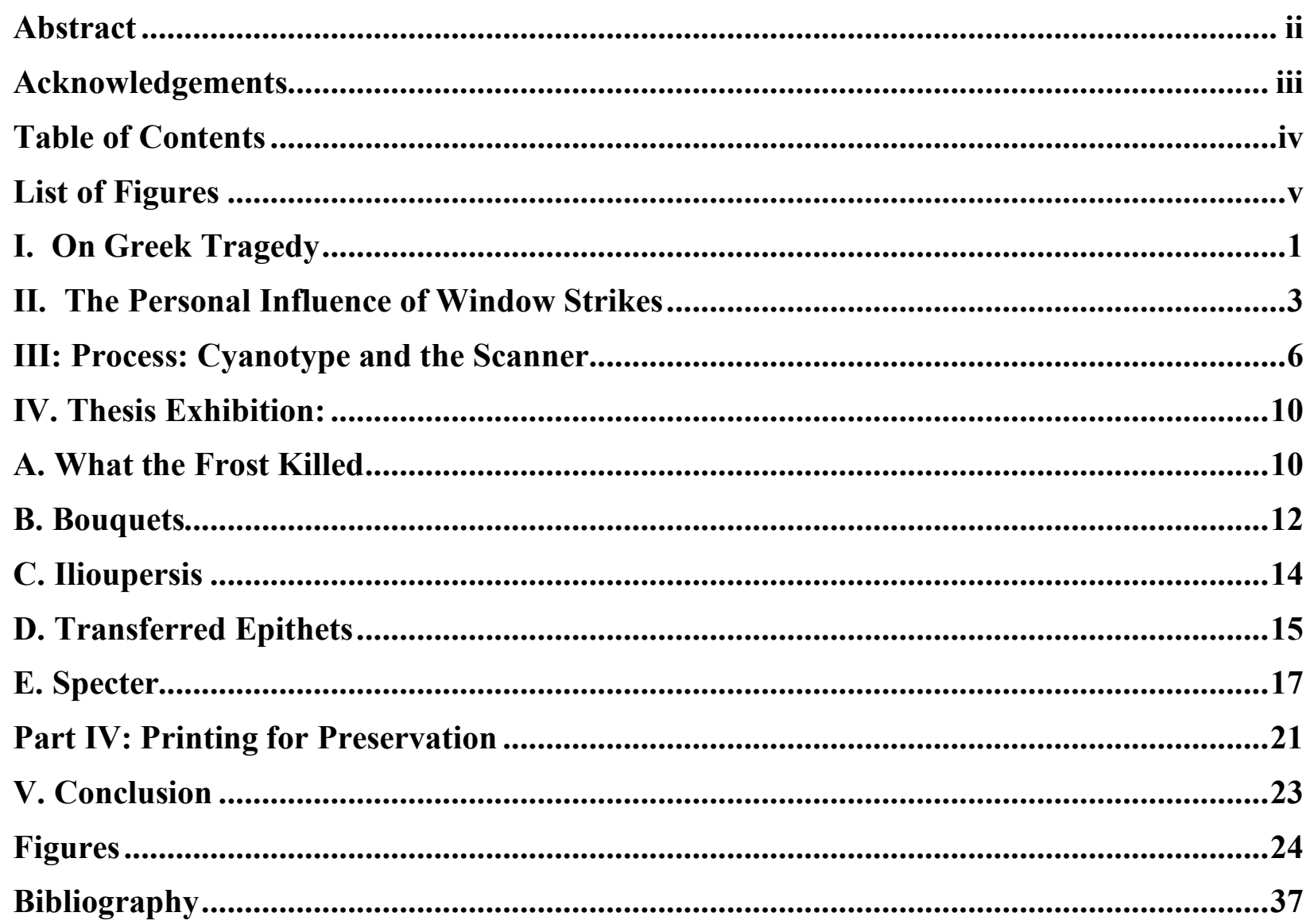




\section{List of Figures}

Figure 1. Allison Semele Blair, The Sparrow.........................................24

Figure 2. Allison Semele Blair, Specter of a Common Songbird.............................24

Figure 3. Albert Renger-Patzsch, Flatirons for Shoe Manufacture, 1928.................25

Figure 4. John Metoyer, Cyanotype Proof of 'Sir John Herschel 's Dream' 2004..........25

Figure 5. Christian Marclay, Unwound Cassette Tape, 2012..........................26

Figure 6. Allison Semele Blair, What the Frost Killed (diptych) ........................27

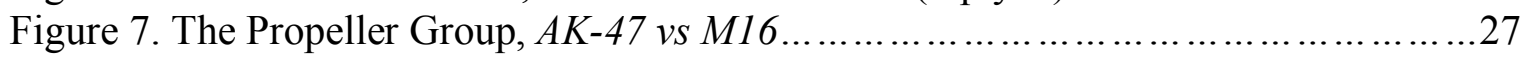

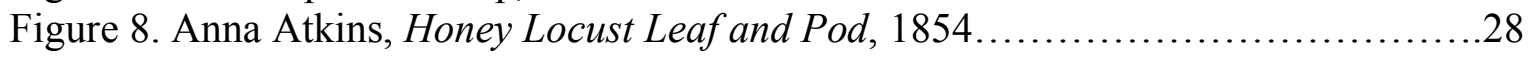

Figure 9. Allison Semele Blair, What the Frost Killed: Bouquets...........................28

Figure 10. Rachel Ruysch, Roses, Convolvulus, Poppies, and Other Flowers, c.1860s....29

Figure 11. Hippolyte Bayard, Still Life with Flowers in Vase, 1846.....................29

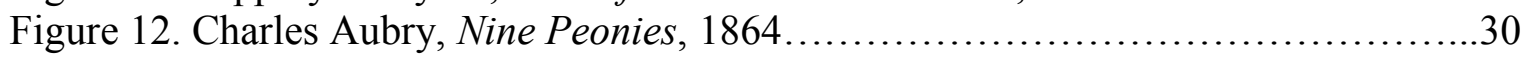

Figure 13. Allison Semele Blair, Untitled ............................................ 30

Figure 14. Allison Semele Blair, Bouquets (detail)....................................

Figure 15. Allison Semele Blair, Ilioupersis ......................................... 31

Figure 16. Allison Semele Blair, Transferred Epithets................................ 32

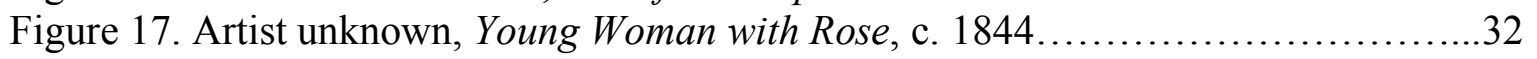

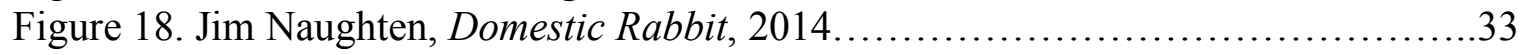

Figure 19. Allison Semele Blair, Specter (installation) ................................ 34

Figure 20. Allison Semele Blair, Specter (cyanotype) .............................. 35

Figure 21. Samantha Parker Salazar, Leukos-Haima v. 2, 2014.......................... 35

Figure 22. Marty Azevedo, Building Steam, 2013................................. 36

Figure 23. Jeffrey Apoian, Float, 2014........................................ 36 


\section{On Greek Tragedy}

"And as for the birds that fly above my head,

I bid them a long farewell,"

Euripides, Hippolytus 1058-59

Prior to pursuing a visual arts career, I spent a decade studying Greek antiquity within the field of Classics. While I have made my professional exit from Classics, Ancient Greek literature and history continues to inform and inspire my art practice.

As an undergraduate, I focused primarily on the political and military history of Athens, which had a radical and complex democracy, but I complimented this study of history by reading lots of tragedies. In particular, I focused on the playwright Euripides, most famous for the Bacchae and Medea. Greek tragedy, unlike later tragedies, belonged to a specific religious context. The tragedies were performed once a year, in trilogies, at a religious festival. The plots of Greek tragedies typically center around complex and unsolvable ethical dilemmas; their heroes are high-born elites brought into these situations by the labyrinthine machinations of irritable gods and the misdeeds of their own ancestors. To solve the unsolvable, Greek tragedies sometimes contrive happy endings for their heroes through a device known as the deus ex machina. In these instances, a god usually arrives at the end of the story to set things right - the matricidal son is pardoned, or the understandably obstinate hero is commanded to cooperate. The web of Greek mythology, which these plays draw from, consists of a multitude of interdependent parts. I admired, and continue to admire, these tragedies for their ethical struggles, their alien atmosphere, and beautiful language. As my undergraduate thesis work was 
primarily historical, there are also moments where the historical context of a play would show through and seem to respond to the Athenian political climate of a particular moment. ${ }^{1}$

In graduate school at The Ohio State University, I became acquainted with the sub-field of classical reception. Reception theory is a component of critical studies, imported to classics relatively recently, largely thanks to Charles Martindale's Redeeming the Text published in 1993. ${ }^{2}$ To put it very simply, Martindale argues that it is impossible to reduce an ancient text to a pure, unadulterated original meaning. Rather, texts are "received" by audiences through the lens of their own contexts. How texts are received by different audiences, and how texts have been adapted and appropriated by different authors in different contexts is therefore interesting and worthy of study on its own. I began to study classical allusions in Modern art and literature, becoming acquainted with various movements of the 19th and 20th centuries, as artists and writers, like Braque and Bulgakov— began to use classical references in loose and innovative ways that related to the world around them. When I shifted my focus to art, much of my work continued to be influenced by and referenced antiquity, with a particular interest in tragedy.

\footnotetext{
${ }^{1}$ For example, the famous passage in Antigone called "Ode to Man" (Sophocles Antigone 332-375) can be interpreted as reflecting Athenian optimism during a period of expansion following the Persian War. ${ }^{2}$ Charles Martindale, Redeeming the Text. (Cambridge: Cambridge University Press, 1993).
} 


\section{The Personal Influence of Window Strikes}

In the middle of my second year of graduate school, I suffered a devastating personal loss that resulted in my gradual exit from classical studies. In the fall of 2011, my husband at the time began manifesting symptoms of an undiagnosed mental illness and suffered a months-long psychotic break. During this time, he became unrecognizably angry, reclusive, and physically and emotionally abusive. During these months, I buried myself in research and writing; during that particular quarter, I was studying Aesop's fables, stories in which animals are used to explain ethics and certain social constructs of the Greco-Roman world. One day my husband left with little warning, and in the aftermath I found it difficult to focus on the minutia and frequently dry prose of academic work. My use of research and writing as a coping mechanism during the most traumatic period of my life strained my relationship with paper-writing, which is the most important component of the $\mathrm{PhD}$. My academic performance, which I had previously allowed to define me, began to decline, and I gradually began to seek out new interests, primarily in visual art. Thankfully, I had the support of my faculty, many of whom had interests in the arts, and I spent the last two years of my graduate study at Ohio State teaching classics, while most of my learning was focused on printmaking, and the intersections I could imagine between the two fields.

My introduction to printmaking was through stone lithography. The iterative qualities of printmaking appealed to me as a classicist - the process of printing, in which a matrix is used to create replicas of an image on paper, is relatable to the process of translation, in which dead languages are replicated in English. Printing in general also reminds me of the hermeneutic chain described in Plato's Ion, in which Socrates tells the famous rhapsode Ion, that his art (and 
perhaps it is implied all or most art) is a mere interpretation of an interpretation of its original source material. ${ }^{3}$ The print process begins with an idea, that is interpreted via image, usually a drawing, which is then interpreted again by the characteristics of the printing medium in general and the specific instance of pulling any particular print. In translating Greek, you have the ideas of the dead author, which have been filtered through centuries of manuscript tradition to create a standard Greek text, which is then filtered again through the abilities and context of the individual translator to create an English interpretation. Much of my work prior to beginning my MFA was grounded in this connection between visual and linguistic translation. For example, I produced a series of prints that attempted to visually mimic the flow of Latin morphology and literary devices in Catullus' sparrow poems (Figure \#1). Printmaking as a translation process remained on my mind as I created my MFA thesis work, particularly in Specter, which is an inkjet print of a cyanotype of a digital scan, adding an additional layer of interpretation.

While I was working in the print shop at Ohio State, I became personally acquainted with the phenomenon of window strikes: birds who die from flying into windows. Hopkins Hall, one of the buildings that house the art department, consists of four stories of floor-to-ceiling, highly reflective windows that fill the workspaces with natural light. I became aware that birds were striking the windows while I worked, and began to draw their corpses. The birds became a fascination for me in part because I felt culpable, as someone who enjoyed these windows on a daily basis. I also find birds an easy source of human projection. I imagined them to be akin to the fallen heroes of Greek tragedies, and related to them on a personal level. At the time, it felt that my prior life had also unexpectedly and calamitously struck an obstacle and died.

\footnotetext{
${ }^{3}$ See Plato Ion 535a — “And so [you rhapsodes] are interpreters of interpreters?"
} 
I worked with the phenomenon of window strikes for several years, culminating in my contribution to the Biopresence exhibition at the Ohio State University in 2015, Specter of a Common Songbird (Figure \#2). I continue to include them in my work, and window strike victims are featured in several pieces in my MFA thesis exhibition, What the Frost Killed. Stemming from my window strike work, this exhibition attempts to make something beautiful out of tragedy. 


\section{III: Process: Cyanotype and the Scanner}

All of the work in my thesis project, and most of my work of the past two years, has combined the print process of cyanotype with imagery collected with flatbed scanner. I began using the scanner to collect reference imagery in early 2014, at the recommendation of Oscar Gillespie, a visiting artist at Ohio State. While I used scanned imagery as a drawing reference, it was not until my second semester of graduate work that I began to explore the photographic potential of the scans themselves. In spring 2016, I began scanning window strikes to create large-format prints. I quickly began to view the scanner bed as akin to a stage, upon which I could enact the tragedies of the birds' downfall and pay them individual homage. I drew classical parallels between my birds and Greek tragic figures based upon the compositions of various images, and gave the resultant prints titles making direct classical allusions. I incorporated my hands in the prints, giving myself the role of Greek gods in myth. I felt as a human that I was complicit in their fall, but as an artist, I could also function in some way as deus ex machina, and give them an apotheosis.

I was also drawn to the objectivity of the scanner and its ability to capture an exact likeness of its subject in extreme, and sometimes uncomfortable, detail. My birds, like Greek heroes, possessed what could be seen as flaws. For example, an American robin, scanned at $12,000 \mathrm{dpi}$, was revealed to have lice. At the time I was looking at the work by the Neue Sachlichkeit or New Objectivity artists, an art movement that arose in Germany in the interwar period. I have always been fascinated by how these supposedly objective paintings reveal so much of the zeitgeist of the1920s and early 1930s. The movement arose as an objection to what was seen as the subjective and sentimental excesses of Expressionism. New Objectivity 
"rejected the sentimentality of Romanticism for a hard-edged realism that was highly ordered and sharply focused." ${ }^{4}$ In photography, the leading photographers were August Sander and Albert Renger-Patzsch. Renger-Patzsch, in Die Welt ist Schoen, published in 1928, featured extreme close-ups of plants and animals, as well as details of industrial buildings and still lives of their products (Image \#3). Thomas Mann called his photographs, "exact statements drawn from the whole - and that's the way it usually is with this man who is, in his way, impassioned. The detail, the objective, is removed from the world of appearances, isolated, sharpened, made meaningful, animated. What more, I would like to ask, has art or the artist done?"5 In a somewhat similar way, I used the extreme close-up of the scanner bed to animate and elevate my subjects, and in the politically uncertain climate of the 2016 presidential campaign, my research into the failing Weimar Republic also felt timely. Ultimately, I decided that my inkjet prints were too objective, and that the colors were too bright and lively to convey the somber content of my Greek tragedy-inspired work.

I found a solution when I added cyanotype printing to my process, which I find adds needed sentiment to the objectivity of the scan. The cyanotype was invented by the astronomer Sir John Herschel in 1842, when he discovered the light sensitivity of iron salts. ${ }^{6}$ To create a cyanotype, one coats paper with a solution of iron salts and allows it to dry in the dark. An object or negative is then placed in contact with the paper and exposed to light. After exposure, the paper is washed in water, which fixes the image and brings out a vivid Prussian blue through the process of oxidation. While Anna Atkins began publishing her cyanotypes shortly after the technique was discovered, the medium did not immediately catch on with art photographers.

\footnotetext{
${ }^{4}$ Paul Martineau, Still Life in Photography (Los Angeles: Getty Museum, 2010), 11.

5 Thomas Mann, "Die Welt ist schön," Berliner Illustrirte Zeitung, no. 52 (1928): 2262-3.

${ }^{6}$ Lyle Rexer, The Antiquarian Avant-Garde (New York: Harry N. Abrams, Inc., 2002), 149.
} 
Among the photography pioneers, Henri Le Secq is one of the few to print in blue. In the 19th century, cyanotype was most often utilized for copying or proofing - it is the source for the term architectural "blueprint", and perhaps its hue gained an industrial association. P.H. Emerson derided the blue print: "No one but a vandal would print a landscape... in cyanotype."7

While it may have been eschewed by many early photographers, the process has experienced broader popularity in more recent times. It is appreciated by contemporary artists for the strangeness of its blue, long tonal range, and temporal possibilities enabled by its long exposure time. There is also a practical appeal to the process - its chemistry is nontoxic, inexpensive, and prints can be made without access to expensive equipment or a dark room. The medium has been used by prominent artists such as Robert Rauschenberg, Robert Fichter, and Chuck Close. A milestone for the medium occurred only very recently. In 2016, the blue print received its first major museum exhibition, Cyanotypes: Photography's Blue Period, at the Worcester Art Museum. ${ }^{8}$ The exhibit featured approximately forty artists, ranging from Atkins to contemporary artists such as Marco Breuer and Annie Lopez, and received positive media coverage. Two contemporary works from the exhibition, which are of great interest to me for their concern with the past, are Cyanotype Proof of Sir John Herschel's Dream (2004) by John Metoyer (Figure \#4), and Christian Marclay's Unwound Cassette Tape (2012) (Figure \#5). In his cyanotypes, Metoyer uses the blue color to express strange or apocalyptic dark settings populated with creatures "that glow as if they had been delivered newly minted from the furnace of creation." "The title of his piece, which depicts a glowing skeleton on an otherworldly stage

\footnotetext{
${ }^{7}$ P.H. Emerson, Naturalistic Photography for Students of the Art (New York: E\&F Spon, 1890), 196.

8 "Cyanotypes: Photography's Blue Period," Worcester Art Museum, accessed April 2018, http://www.worcesterart.org/exhibitions/cyanotypes-photographys-blue-period.

${ }^{9}$ Lyle Rexer, The Antiquarian Avant-Garde (New York: Harry N. Abrams, Inc., 2002), 109.
} 
surrounded by model planets, refers to the inventor of the process. Marclay's piece, Unwound Cassette Tape takes advantage of the cyanotype's ability to record the passage of time. Marclay unspooled a cassette tape on an emulsion-coated paper as it was exposing, resulting in a variety of hues depending on exposure time and distance of the tape from the paper. The nostalgic blue dovetails with Marclay's interest in materials that are nearly extinct: "Cassettes are obsolete, captured by an obsolete photo technique," he said. "Two dying technologies."10

There is a particular atmosphere created in the intersection of the digital scan and the cyanotype, at least as I produce them. In my prints, the scanner provides a specific kind of light that acts as an even spotlight on anything that was immediately against the glass. There is also little depth, as imagery not immediately in the foreground rapidly fades into a murky dark blue background. In this atmosphere, I found something akin to the feeling of Greek tragedy. It is as if my birds and flowers are suspended as shades in the quiet Underworld of mythology. My prints have a romantic, aesthetic quality, but the blue also keeps them strange. While Greek tragedies possess beautiful language and ethically complex stories, the foreign and cryptic aspects of these fragmentary texts have also long appealed to me. I believe that the blue has a transformative effect on my imagery, and shifts the tone of my prints to a stranger and less straightforward and scientific plane. This tonal shift assists in making my birds more mythic and heroic, while the nostalgic qualities of the prints signal a link to the past. I am not alone in seeing this transformative effect of cyanotype blue. In his assessment of Mike Ware, a cyanotype process innovator, Lyle Rexer writes that his "blues are so intense they lift his landscapes out of the quotidian and into the archetypal."11

\footnotetext{
10 Ted Loose, “Cyanotype, Photography’s Blue Period, Is Making a Comeback,” NYT, Feb. 5, 2016.

${ }^{11}$ Lyle Rexer, The Antiquarian Avant-Garde (New York: Harry N. Abrams, Inc., 2002),109
} 


\section{Thesis Exhibition:}

\section{A. What the Frost Killed}

My MFA thesis, What the Frost Killed, consists of twenty framed works, divided into four groupings, and a single large-scale, multi-panel wall installation. The works shown are primarily hand-printed cyanotypes, with one large inkjet reproduction of a cyanotype. All prints depict digitally-scanned plants and animal life that died during the years 2016-2017, a particularly politically turbulent time period in the United States surrounding the election of Donald Trump.

The titular piece, What the Frost Killed, is a diptych of two nearly identical images of plant matter pulled from my personal garden the week of the November 2016 election, which coincided with the first hard frost of the year (Figure \#6). The image chosen for my thesis was one from a series of cyanotypes of the same name, printed either from digital negatives or by placing plant matter directly on the chemistry coated paper. The prints were exposed in natural sunlight, rather than the UV box, to record the impression of the light of a very specific time. The prints were then toned using black tea, which results in a dark blue hue with tan highlights, and a deeper level of contrast. To express some of my feeling of chaos at this moment, I allowed some of the brush strokes from the cyanotype coating to remain visible, and for irregular pooling in the toning process, which creates a slightly distressed and faded appearance. The plants I used in this series included vines, basil, and flowers. I emphasized marigolds for their seasonality and strong association with death, especially in Mexican Day of the Dead ceremonies. The transformation of the bright colors of these flowers into a dull and monochromatic dark blue struck me as particularly sobering, as it significantly deadens their appearance. 
When I first printed the series in November 2016, it was a response to the sudden and allconsuming sense of crisis I, and many others, felt in the immediate wake of the election of Donald Trump as President of the United States. This feeling persisted throughout the year, so I repeated the exercise a year later. I chose one image from the original series, primarily for the strength of its composition, re-edited the image, and printed it with a new negative in the sunlight of election week, 2017. In my thesis, I displayed the two nearly identical pieces together, to represent the sameness of the national climate, at least from my perspective, a year apart. As the political content of my work is not immediately obvious to the viewer and requires knowledge of the process used to create the print, I provide the viewer with explanatory wall labels and an exhibition artist statement. ${ }^{12}$ The reliance on text to explain the political context of work is employed by other artists, notably the Propeller Group. In a portion of the collective's piece $A K$ 47 vs. M16, (image \#7) the viewer is presented with sculptures of clear gel blocks containing the abstract hollows created by the collision of two bullets. While the title provides a clue as to how they are made, the specificities of the construction of the piece and its inspiration from several wars can only be gleaned by reading their artist statement. ${ }^{13}$ As the political message of my piece is direct, and the exhibition carries the same title and convey similar imagery, the viewer is welcome to make the assumption that all of the work in some way responds to the election.

Much of my thesis work is informed and inspired by the history of art and its context. As someone who spent a decade immersed in the pursuit of antiquity, I am perpetually looking backward. These prints borrow from the work of Anna Atkins, who produced one of the first

\footnotetext{
12 Wall text reads: "This work documents what died in my garden the week of the 2016 election, which coincided with the first hard frost of that year. The first print was exposed in the sunlight of that time. I repeated the process in 2017."

13 “AK-47 vs. M16,” The Propeller Group, 2015, accessed April 2018. http://www.the-propellergroup.com/ak-47vsm16
} 
photographic books, and one of the first to use the cyanotype in an art-related context. ${ }^{14}$ Atkins used the process over the span of a decade, 1843-1853, to document British algae and later ferns (Figure \#8). She made her impressions by placing the desiccated plants directly on top of the emulsion-coated paper and exposed the prints under glass in direct sunlight. Her first installment of British Algae: Cyanotype Impressions was published in 1843, slightly before William Henry Talbot's The Pencil of Nature introduced the world to the kallitype. ${ }^{15}$ Photography was new enough that Talbot felt the need to inform his readers in a note that his images were not engravings. ${ }^{16}$ Like Atkins' volumes, What the Frost Killed is a documentary work recording botanical specimens. These prints rely on direct sunlight, and the earliest prints I made in the preliminary series contained photograms. However, I ultimately decided to use imagery captured by scans rather than the abstract impressions left by the bodies of the actual plants, as I wished to capture more detail.

\section{B. Bouquets}

In an extension of my What the Frost Killed diptych, I continued to document the plants and flowers that died in my immediate surroundings throughout 2017, in a series I call What the Frost Killed: Bouquets (Figure \#9). These works were created in individual series throughout the year, primarily at moments that I found the political actions of the government to be particularly appalling. These moments include the building and eventual passing of the tax reform bill, which I fear will ultimately have dire consequences for government spending on

\footnotetext{
${ }^{14}$ Anna Atkins, Photographs of British Algae: Cyanotype Impressions, published privately, 1843. ${ }^{15}$ Edwin Dobb, "Sun Gardens: Anna Atkins and Her Botanical Blueprints," The Sciences vol. 25, no. 6 (1985): 35. ${ }^{16}$ Ibid.
} 
important social services, and the attempted repeal of the Affordable Care Act. While many of these political acts were catalysts for making work, I acknowledge there is no direct relationship between the image and these events. Nor was it my intention to literally illustrate these events. I selected ten 10 " x 8 " prints from a larger body of work and displayed them chronologically in a single row. To connect them visually with the What the Frost Killed diptych, I placed the two print groups adjacently, and utilized the same frames. This work is framed in natural wood frames with no staining, so as not to interact with the color of the prints, and without glass to prevent glare.

Bouquets is funereal in intent, presenting the viewer with dead flowers to mourn the passing of an uncomfortable year. These floral images draw the floral still life tradition, and from Victorian folk imagery. Flowers are a staple of still life compositions, and frequently have a memento mori connotation. In painting, floral still lives were particularly popular among 17 th century Dutch painters, such as Rachel Ruysch (Figure \#10). A revived interest in these Dutch paintings occurred in Paris in the mid-19th century, a period I find interesting in photography. In early photography, still life featured prominently in the early experiments of Hippolyte Bayard, William Henry Fox Talbot, and Jacques Louis-Mande Daguerre, pioneers of the medium. I am interested particularly in the beautiful but melancholic images still lives with dropped petals, such as Hippolyte Bayard's 1846 Still Life of Flowers in a Vase (Figure \#11), or Charles Aubry's 1864 Nine Peonies (Figure \#12). In his monograph Painting and Photography, Dominique de Font-Reaulx discusses the technical advantages of still life for $19^{\text {th }}$-century photographers, but also posits the artistic side of Daguerre's work: "The artistic intention too is tangible; the images composed by the French inventor and his early followers exude a subdued, melancholic 
nostalgia." ${ }^{17}$ I mimic this melancholic nostalgia by using very traditional subdued imagery, and by toning some of the cyanotypes. The toning causes a slight bleaching, which has an additional antiquing effect, and can be seen in this untitled image of an alstroemeria (Figure \#13).

Bouquets also references a pervasive image in Victorian folk art, that of the disembodied hand holding a nosegay, the small bouquets popular in the culture of the time. These images appear on various personal and household items, ranging from calling cards to jewelry to furniture decorations (Figure \#14). Half of the images in Bouquets depict hands holding picked or cut flowers. The exact range of meanings behind the Victorian images is not entirely clear, as they appear in such varied contexts, and the Victorians often encoded their use of different flowers. A wide range of flower dictionaries were published throughout the $1800 \mathrm{~s}$ in both Europe and the United States, beginning with Charlotte de la Tour's Le Langage des Fleurs in 1819. ${ }^{18}$ I ascribe no particular symbolism to the species of flowers in Bouquets, as they were simply what happened to die near me at the time All but one of the hands in the images are mine, which I use to reinforce the funerary nature of the images, as I have visible tattoos of skulls (Image \#15). While hands in the window strike images can represent the deus ex machina, in the bouquet series they are more of a representation of complicity, as well as human mourning and suffering.

\section{Ilioupersis}

Ilioupersis is a grouping of three 14"x11" prints displayed on the wall opposite the What the Frost Killed diptych (Figure \#16). This grouping was curated from a series of prints that I

\footnotetext{
${ }^{17}$ Dominique de Font-Reaulx, Painting and Photography (Paris: Flammarion, 2012), 181.

${ }^{18}$ Charlotte de la Tour, Le langage des Fleurs (Paris: Audot, 1819).
} 
chose to give special prominence because of an implied narrative movement across the series. The three prints depict two hands holding a desiccated stem of alstroemeria. As the hands reposition the plants, the flower becomes increasingly destroyed. As the viewer moves across the prints from left to right, the flower loses nearly all of its petals. Due to space constraints in the gallery, two prints were eliminated from the series. I chose to include the prints that featured more dynamic movement in the position of both the petals and hands. I printed Ilioupersis with a higher level of contrast than other prints by increasing the exposure time to increase the sense of drama. The title is the Greek word for the Sack of Troy, a mythical event in which the Greeks, through deception, destroy and plunder the city of Troy, ending the Trojan War. This scene from mythology was on my mind as I reworked these prints during the debate on tax reform. While it is unlikely that the viewer will understand the reference of the title, I believe the destruction in these particular prints is obvious.

\section{Transferred Epithets}

Transferred Epithets evolved from a series of cyanotypes of dead birds inspired by Greek tragedy when I first began working with the medium, in Fall 2016. In the production of these earlier prints, I realized that the peculiar blue and nostalgic image quality that results from the process created an atmosphere akin to my experience of the register of Greek tragedy. Transferred Epithets is a series of five 11"x14" prints of dead birds, arranged in a grouping of four (Figure \#17). The fifth print is centered on the door set into the wall of the gallery, in order to fill a particularly awkward location. The title is a literary device most often used to describe a misapplied adjective, for example, a "sleepless night." I associate the word "epithet" with the poetic titles used for figures in Greek mythology. When displayed individually, each of the five 
pieces bears an individual title alluding to Greek tragic figures, which I believe helps to elevate the birds individually. My connection between Greek tragedy and cyanotype, and the circumstances surrounding the death of the birds is explained in the wall text beside the piece. ${ }^{19}$

The primary intent of this work is to memorialize birds who die from human perpetuated causes. All five prints depict birds who are the victims of either window strikes or were killed by pet cats: unidentified sparrows, a wren, and a hummingbird. I chose a larger print format than in Bouquets, to allow for greater detail and resolution in my image to highlight the individual beauty of the birds. In all but one image, the birds are together with human hands, who either raise them up or seem to thrust them down.

These images are also inspired in part by the tradition of post-mortem daguerreotype, which I encountered at the exhibition Securing the Shadow: Posthumous Portraiture in America at the American Folk Art Museum in December 2016. Like my prints, many of the daguerreotypes are aestheticized, and feature corpses that are posed to look as though still alive (Figure \#18). I am certainly not the first contemporary artist to use a 19th century technique to make post-mortem prints of dead animals in order to memorialize them. For example, Jim Naughten makes stereoscopic images of macabre Victorian biological specimens (Figure \#19). In a review for Hyperallergic, Allison Meier writes, "Naughten photographed each one straight on, giving all the animals, whether great or small, a quiet dignity, even if they're in a flayed state. ${ }^{20}$

${ }^{19}$ Wall text reads: "In my work, I memorialize wildlife killed by human causes. Inspired by Ancient Greek epic and tragedy, I engage with the ethical dilemmas inherent in our actions to express the strange, intractable beauty of these unsung deaths. Focusing on birds who die by window strike, I seek to honor and elevate the individual victims of a systemic problem."

${ }^{20}$ Allison Meier, ““"The Relics of Victorian Natural History in Eye-Popping Stereoscope,” Hyperallergic, May 24th, 2016, https://hyperallergic.com/300647/the-relics-of-victorian-natural-history-in-eye-poppingstereoscope. 


\section{E. Specter}

Specter is the central piece of my MFA thesis exhibition, rising floor-to-ceiling in the middle of the back wall, and visible from the lobby (Image \#20). It is a 14'8" x 11' 8 " inkjet reproduction of a cyanotype, sized to fit the back wall of the Mesaros Gallery, and printed on forty-two individual sheets of Stonehenge paper. The installation is tiled together and attached to the wall with staples. The staples largely disappear from the eye, but the seams are visible.

The image is derived from a digital scan of a small wren with outstretched wing being held against the glass by human fingers, one of which has a particularly jagged nail. The bird is raised above a landscape of dead marigolds. The image comes from my late 2016 series, Wooden Walls/Second Ships. Like What the Frost Killed, Wooden Walls was a series of prints that reacted to the post-election political climate in the United States, as I wondered what to do in the face of what felt like impending social, economic and political destruction. In this series of prints, I created sets of ghostly landscapes from garden detritus - the same, but further desiccated, marigolds from What the Frost Killed —and inhabited them with a window strike. The Wooden Walls/Second Ships title refers to a particularly bleak moment in Ancient Greek history, when the Greeks had been defeated by the Persians at Thermopylae and were looking at imminent defeat at the hands of the invading Persian army. At the last moment, the Athenian statesman Themistocles is able to interpret a vague oracle about wooden walls as a call to invest in the Greek navy and take the Persians in a sea battle (Herodotus 7.143). ${ }^{21}$ This idea led the

\footnotetext{
21 "Now there was a certain Athenian, by name and title Themistocles son of Neocles, who had lately risen to be among their chief men. He claimed that the readers of oracles had incorrectly interpreted the whole of the oracle... Correctly understood, the gods' oracle was spoken not of the Athenians but of their enemies, and his advice was that they should believe their ships to be the wooden wall and so make ready to fight by sea. When Themistocles put forward this interpretation, the Athenians judged him to be a better counsellor than the readers of oracles, who would have had them prepare for no sea fight, and, in short, offer no resistance at all, but leave Attica and settle in some other country." (Trans. AD Godley, 1920).
} 
Greeks to win the next battle, and ultimately the war to maintain their independence. My prints similarly hoped to make something out of bad tidings — to build worlds out of dead things and in this way present an uncertain and grim expectation for a future.

Specter is an experiment, my second attempt at a two-dimensional, pictorial site-specific installation. The title alludes to the first, Specter of a Common Songbird, which was part of the Biopresence exhibition at the Ohio State University, organized by Amy Youngs in 2015 (Figure \#2). Common Songbird was an inkjet reproduction of an etching of a window strike, installed at monumental scale in three stories of windows on the very building that killed the bird. As Biopresence was an ecologically-minded exhibition about the interaction between human beings and animals on campus, my piece was simple. I magnified the small victim of a systemic problem to match its magnitude. While precise numbers vary between studies, research suggests that as many as 94-97 million birds die from striking windows each year in the United States. ${ }^{22}$ While I accomplished what I had set out to do, the installation process itself was rife with technical issues and elements that had to be improvised due to unexpectedly varying window hardware. I had gained an interest in installation from working with Sam Salazar Parker (Figure 21, and Marty Azevedo (see Figure 22), and from witnessing several of Ann Hamilton's multidisciplinary works, particularly the city is a blank stage (2015) and the common SENSE (2014). ${ }^{23}$ All of these artists had constructed paper-based installation projects, and I decided to use my MFA exhibition as an opportunity to refine my process.

\footnotetext{
${ }^{22}$ D. Klem Jr. "Collisions between birds and windows: Mortality and Prevention," Journal of Field Ornithology 61(1990):120-128.

For more information on bird deaths from window strikes and related causes like wind turbines, see the Wildlife Conservation Society's annotated bibliography: https://abcbirds.org/wpcontent/uploads/2017/02/Window Collision Bibliography-February-2017.pdf

${ }^{23}$ In the common SENSE, Hamilton utilizes inkjet prints of birds on newsprint to create ephemeral giveaways for her audience, and the aesthetic of the prints and installation most certainly influenced my earliest graduate school inkjet prints.
} 
All of my thesis work utilizes a combination of old and new processes. Specter combines the 19th century cyanotype for its soft, nostalgic aesthetic and evocative color, the high resolution, shallow field of depth, with the illumination of the desktop flatbed scanner. This process adds the digital manipulation of the large format inkjet printer to my work. To create the image, I scanned an original 8" x 10" cyanotype at 2400 dpi, enlarged it in Photoshop, and separated the tiles into individual files for printing. The tiles are printed on 22 " x 30 " sheets of Rising Stonehenge fine art paper, which has a smooth vellum surface that works well with inkjet printing, and is sturdy enough to endure significant handling during installation. Earlier inkjet experiments with rice papers, newsprint, and matte printmaking papers were too fragile. While Specter was designed for the Laura Mesaros Gallery specifically, it was my intent to keep the panels as intact as possible upon disassembly, so that it can be put up again if another opportunity arises. As the paper is archival, it does not need to be a purely ephemeral piece. As process is an important aspect of my work, I allowed the nature of the enlargement and inkjet printing to remain visible. Nearly invisible features of the original print, like specks of dust or tiny dots created by the paper texture, are clearly visible in the installation to the close observer. While the hue of the inkjet prints is the similar to that of the hand-printed cyanotypes in the exhibition, the color does not match exactly. I also allowed the tiles to have obvious but not distracting seams, which almost disappear at important focal points.

The addition of inkjet reproduction expands the possibilities for my work, especially in terms of magnitude, as it allows the visual effects of a single cyanotype to be expressed at a size that the medium itself cannot readily accommodate while maintaining the level of detail I prize in my imagery. In an early testing period, I tiled together an image from individually printed cyanotypes, but found the resultant variation in the blues too distracting for my purposes. Other 
artists use this variation to great effect, such as the New York-based photographer Jeffrey Apoian, who used the varying blues to mimic the appearance of the Aegean Sea in his 2014 installations Swim and Float (Figure 24). Inkjet printing, on the other hand, allows for total control and consistency in color reproduction, while enlargement makes visible artifacts from the original printing process that would not normally be seen by a cyanotype viewer.

There is also an undeniable power and impact of large-scale art. As a classicist studying in Greece, I have spent much time with the monumental art and architecture of antiquity. The Parthenon is not more beautiful than the much smaller Hephaisteion, another Doric, mid-fifth century temple in Athens, but the effect of the magnitude of the Parthenon on the viewer, who is dwarfed by it, is direct. By most scholarly accounts, because of its enormity and position on the Acropolis, the building is "the monument which most vividly embodied the experience and aspirations of its age." 24 By manipulating its scale and giving it a central position in the gallery, I intend to make my image more vivid and powerful. Through exponentially increasing the size of the bird, I hope to imbue it with an exaggerated importance by making it larger than the viewer.

${ }^{24}$ J.J. Pollitt, Art and Experience in Classical Greece (New York: Cambridge University Press, 1972), 71. 


\section{Part IV: Printing for Preservation}

As a longtime student of classical history, I am persistently reminded of the parallels between the past and the present, and I am also particularly aware of how easily the past can be lost to us. In my art practice and my teaching, I borrow the motto of Nashville-based letterpress shop Hatch Show Print, "Preservation Through Production." 25 While the cyanotype and alternative process photography in general have become more popular, and the possibilities for their employment have expanded immensely with the advent of Photoshop and the digital age, this popularity is by no means universal. In a time of shrinking academic budgets and a growing desire for art departments and universities to acquire the latest technology, I do not take for granted the stability of silver or iron-based photography, or, for that matter, the lithography or intaglio processes that introduced me to the potential of printmaking. As I believe the cyanotype process continues to be relevant and useful in art making, it seems prudent to further its continuation through producing, teaching, and displaying the process in my work. It is not difficult to learn to create a cyanotype, but there is skill and technique in using it well. I have seen significant improvement in the quality of my images over the course of my graduate study, but I have not yet perfected my methods. The many variables in paper, emulsion saturation, age of solution, drying time, exposure time, and creation of the digital negative make it nearly impossible to produce two completely identical prints. This slight unpredictability and individual nature of each print is appealing to me, as it captures subtly the hand of the printer and

\footnotetext{
${ }^{25}$ Dave Margulius, "Preservation Through Production at Hatch Show Print," Collectors Weekly, Sep. 9, 2009, accessed April 2017, https://www.collectorsweekly.com/articles/preservation-through-productionat-hatch-show-print/
} 
the exact time and circumstances of its printing. I find the individual nature of these prints particularly suitable for my images memorializing individual plants and birds. 


\section{Conclusion}

What the Frost Killed, my Master of Fine Arts Thesis exhibition, is a collection of prints memorializing the birds and plants that died around me in the years 2016-2017. Drawing from my background as a student of Classics, my work is loosely inspired by Greek tragedy. I have found some of the feeling of Greek tragedy in the combination of the digital scan and the 19th century cyanotype. I utilize the scan for the objectiveness and clarity of its imagery, while the cyanotype process adds a romantic, nostalgic, and strange aesthetic that I find adds needed sentiment for my funerary work. The titular piece in the exhibit was created as a direct response to November 2016 election of Donald Trump. As the aftermath of the election weighed heavily on me for the entire year, I view the rest of my work in the exhibit as an indirect response to what for me is a persistently tense and destabilizing political environment. What the Frost Killed mourns for the victims of a particularly turbulent year.

My thesis project was time-specific, recording images to mark the passing of birds and plants in a specific time, 2016-2017. I plan to continue my work in a similar vein throughout the remainder of the current presidential term, making changes in style, medium, and imagery to match my perception of the tone of the political climate. In my eyes, 2018 feels different than the preceding year, as the constant sense of instability begins to normalize. I am currently interested in the aftermath of the political events that occurred in 2017. This interest has led me to begin Thaw, a series of scans documenting objects and detritus that were uncovered in my surroundings during the spring thaws of 2018. 


\section{Figures}
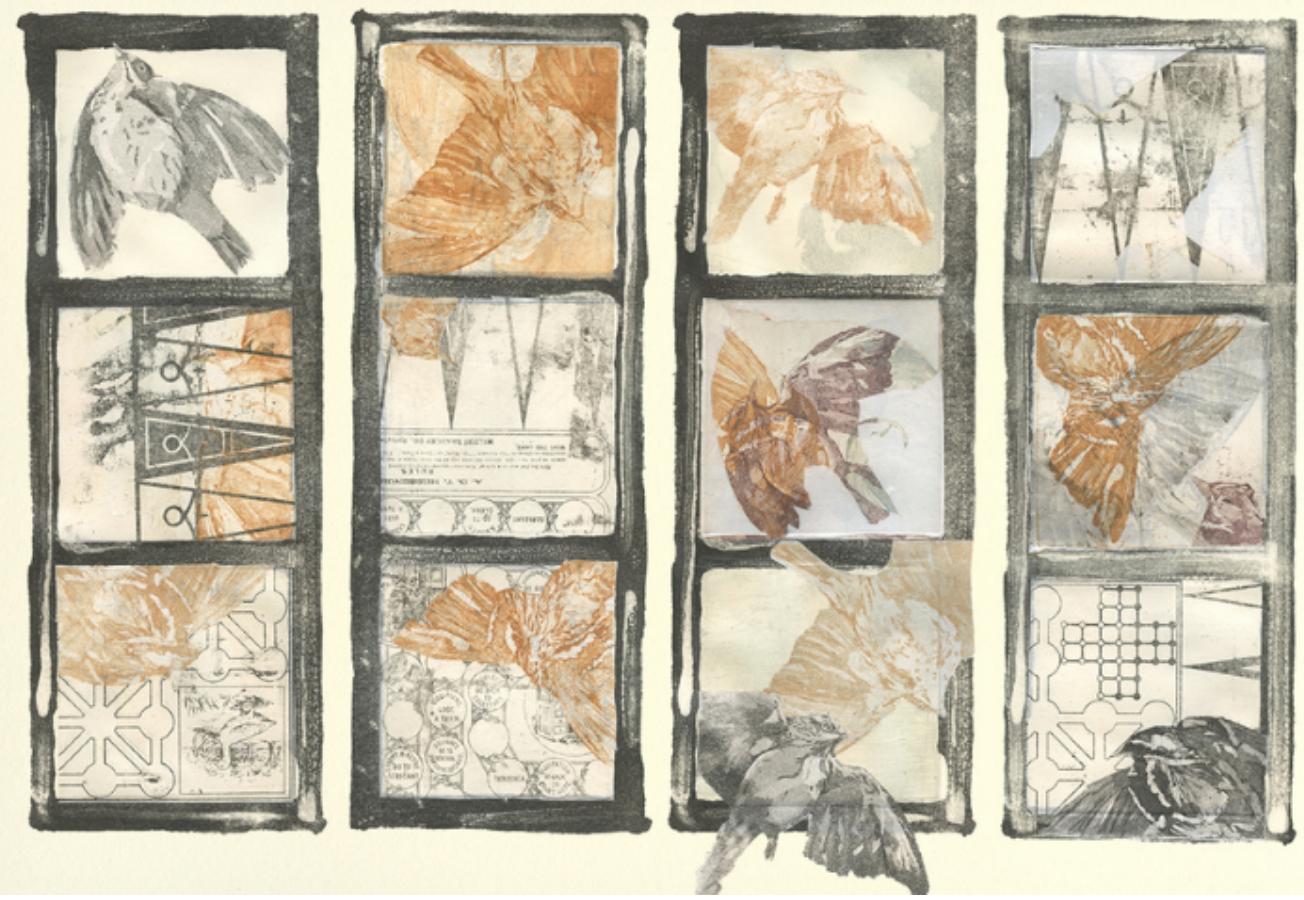

Fig. 1. Allison Semele Blair, The Sparrow: Visual Translation of Catullus 2, 2014, etching, lithography, and chine-colle.

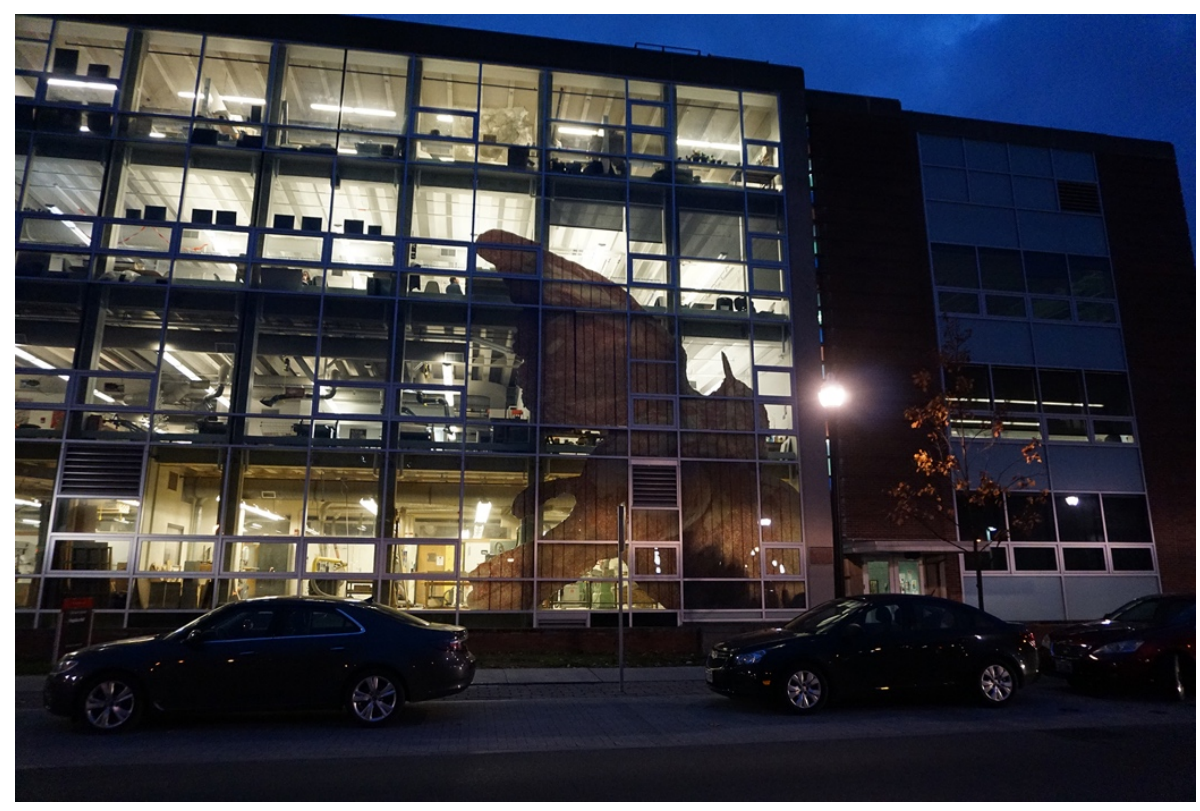

Fig. 2. Allison Semele Blair, Specter of a Common Songbird, 2015, etching on newsprint. (Photo courtesy of Amy Youngs.) 


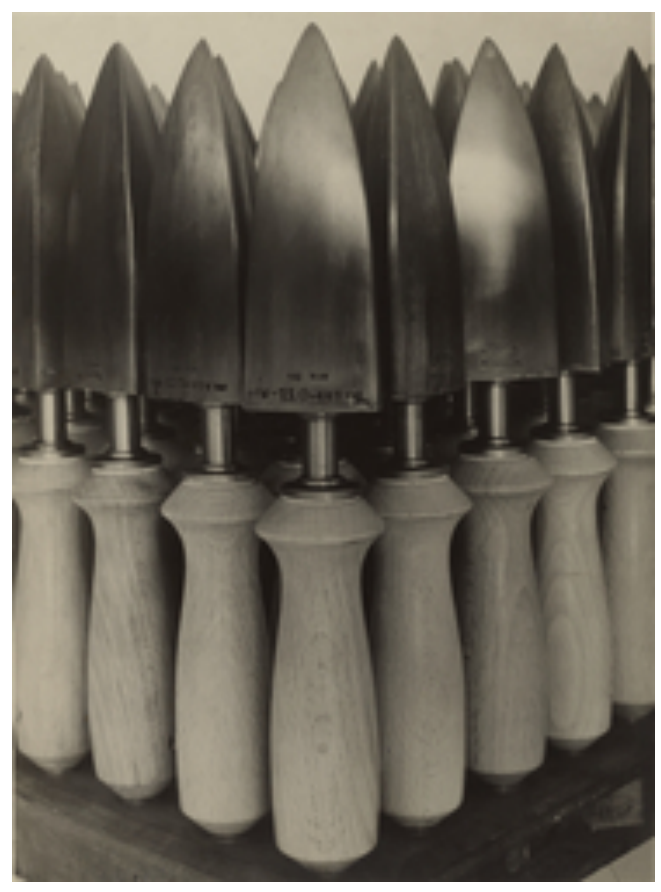

Fig. 3. Albert Renger-Patzsch, Flatirons for Shoe Manufacture, 1928. Accessed from http://www.getty.edu/art/collection/objects/34945/albert-renger-patzsch-flatirons-for-shoemanufacture-german-1928/ (accessed April 10th, 2018)

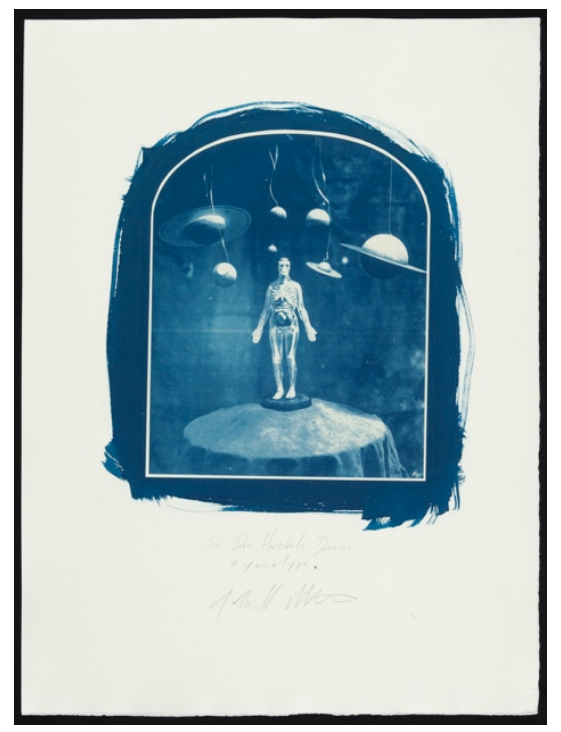

Fig. 4. John Metoyer, Cyanotype Proof of 'Sir John Herschel's Dream,' 2004, cyanotype. Accessed from http:/hyperallergic.com/wp-content/uploads/2016/02/cyanotype4.jpeg (accessed April 10th, 2018) 


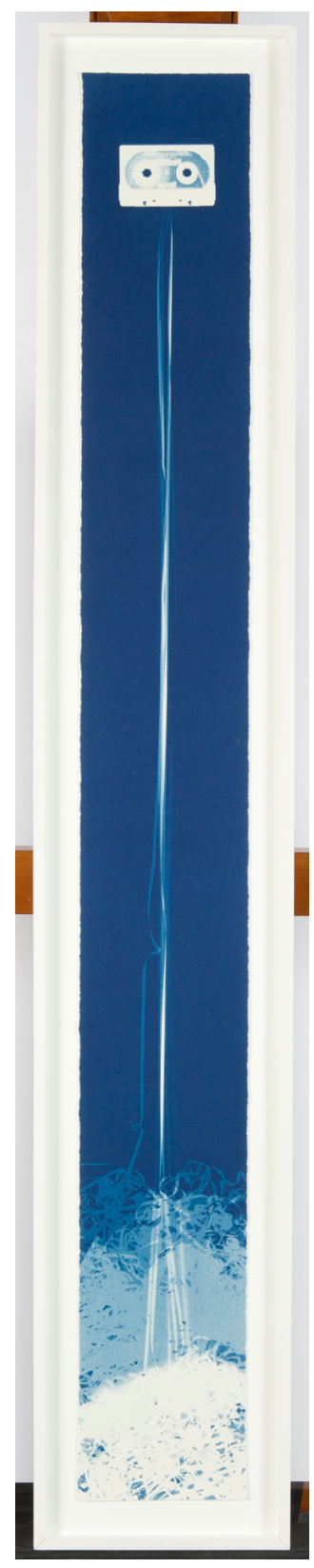

Fig. 5. Christian Marclay, Unwound Cassette Tape, 2012. Accessed from https:/hyperallergic.com/272915/photographys-blue-period-gets-its-first-major-show-in-the-us/ (accessed April 10th, 2018). 


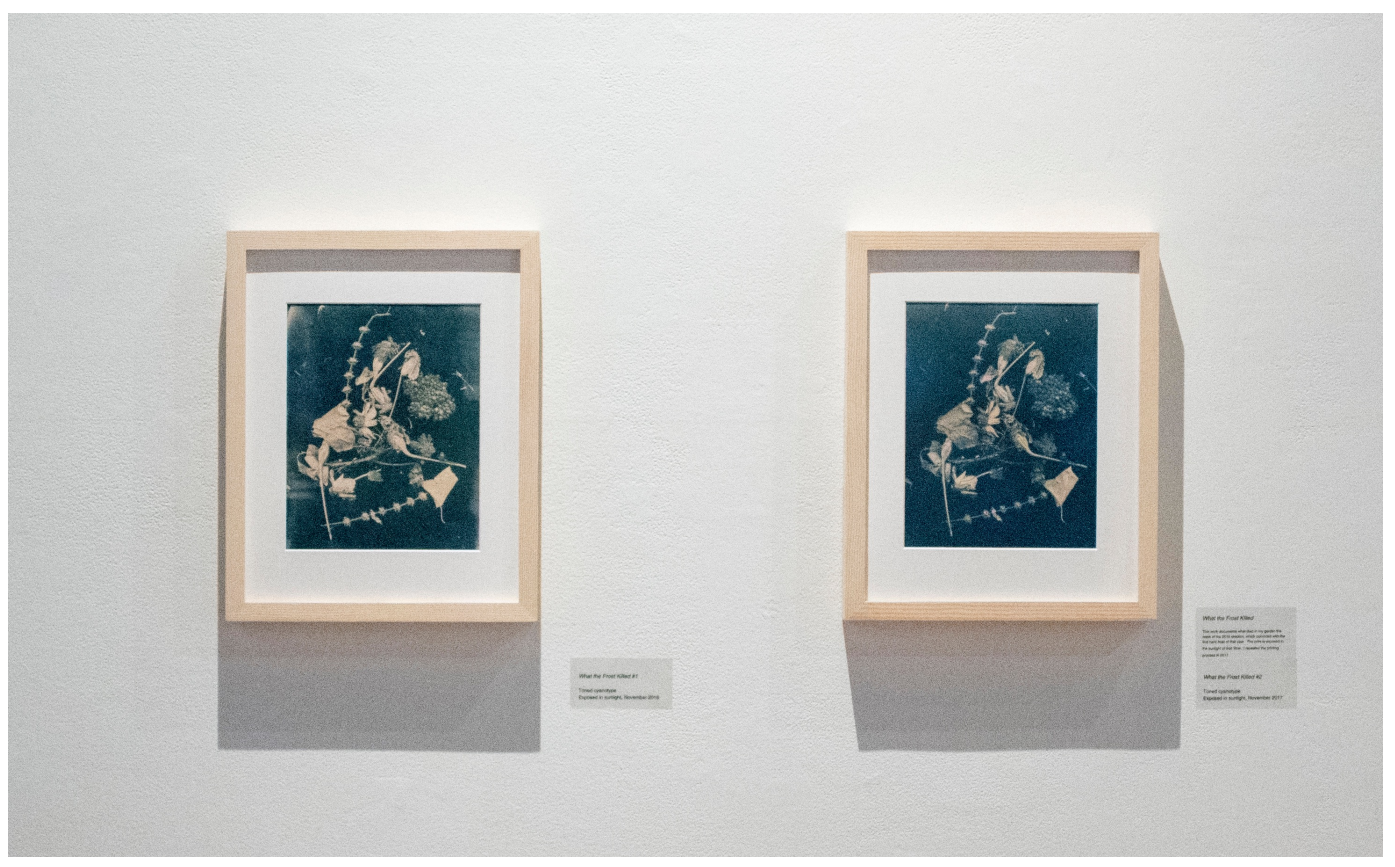

Fig. 6. Allison Semele Bair, What the Frost Killed, 2016-2017, toned cyanotype.

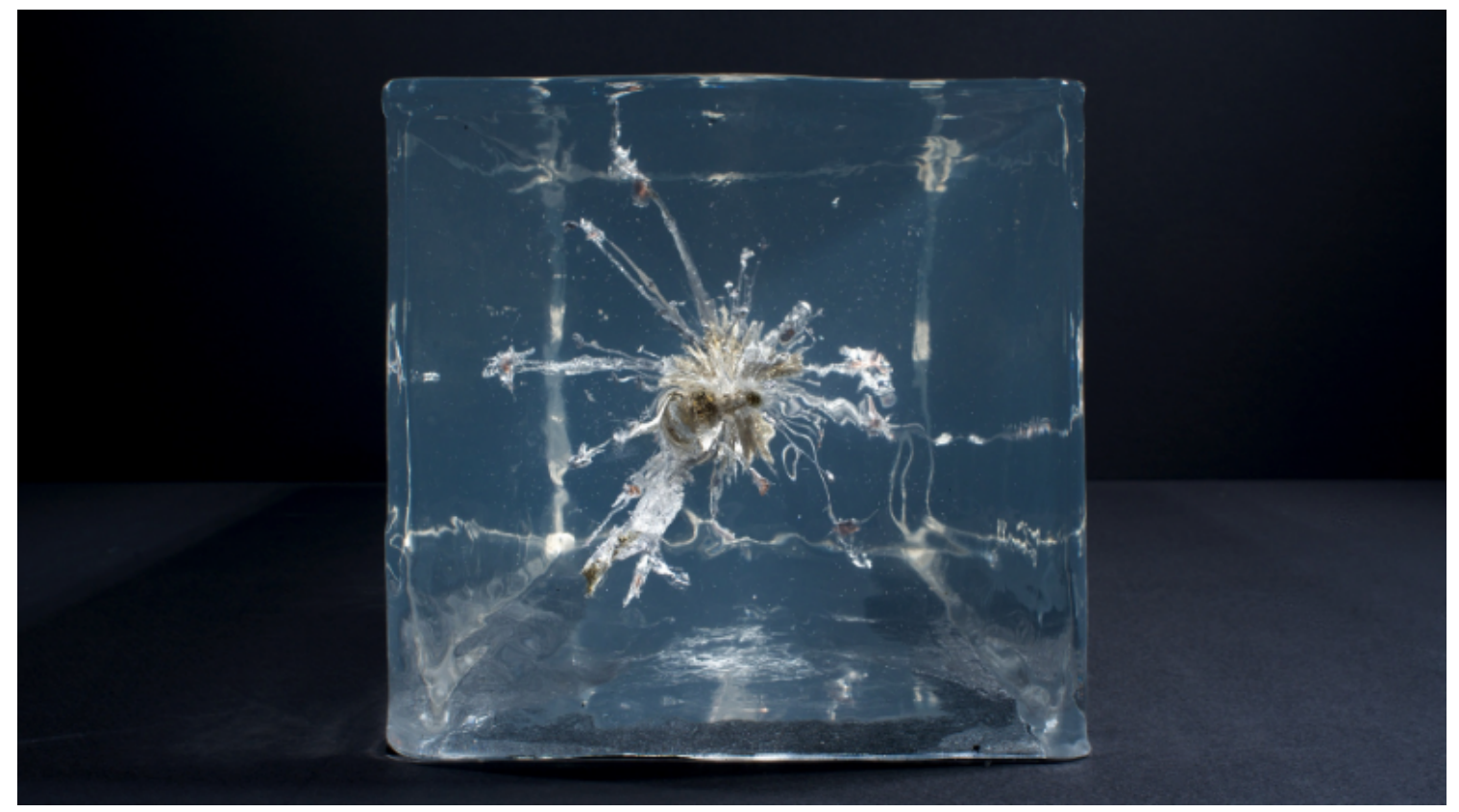

Fig. 7. The Propeller Group, AK-47 vs. M16 (detail), 2015, gel block sculpture. Accessed from http://www.the-propeller-group.com/ak-47vsm16 (accessed April 10th, 2018). 


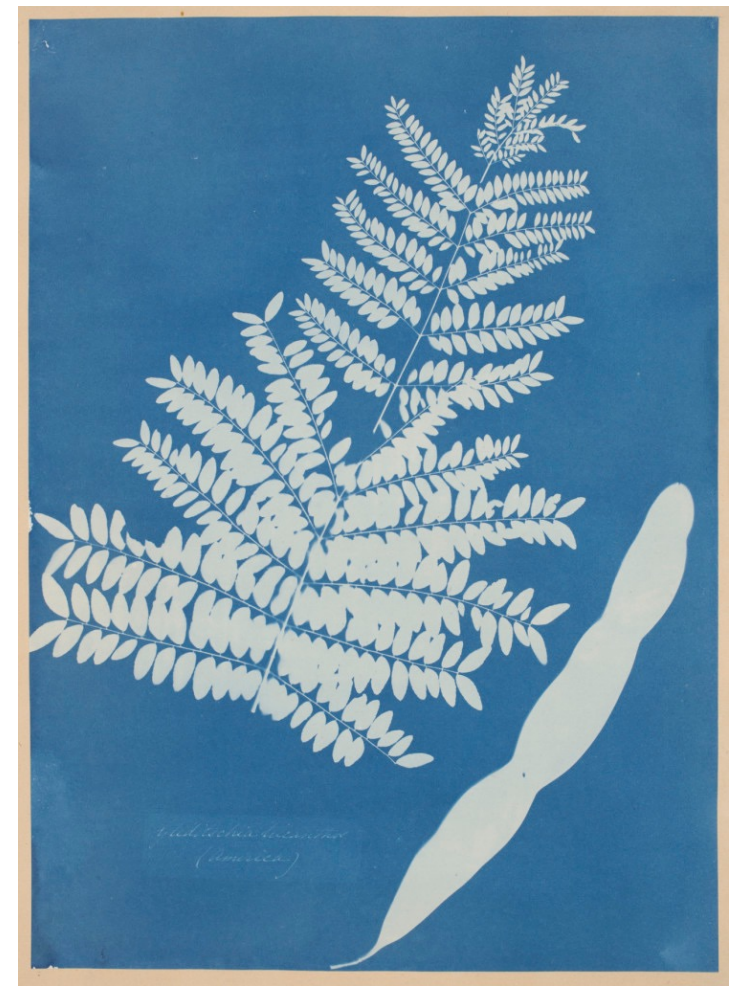

Fig. 8. Anna Atkins, Honey Locust Leaf and Pod (Gleditsia Triacanthos), c. 1854, cyanotype. Accessed from https://hyperallergic.com/272915/photographys-blue-period-gets-its-first-majorshow-in-the-us/ (accessed April 10th, 2018).

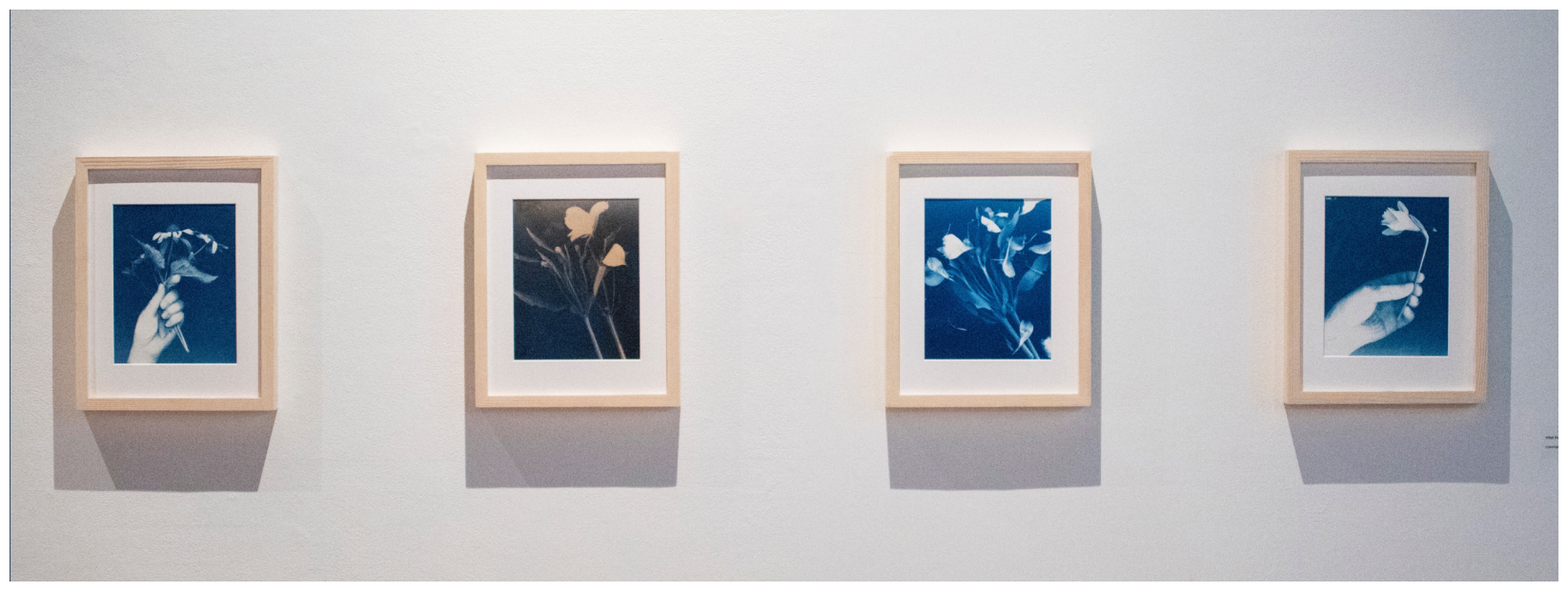

Fig. 9. Allison Semele Blair, What the Frost Killed: Bouquets (selection), 2018, cyanotypes and toned cyanotypes. (Photo courtesy of Michael Oliver). 


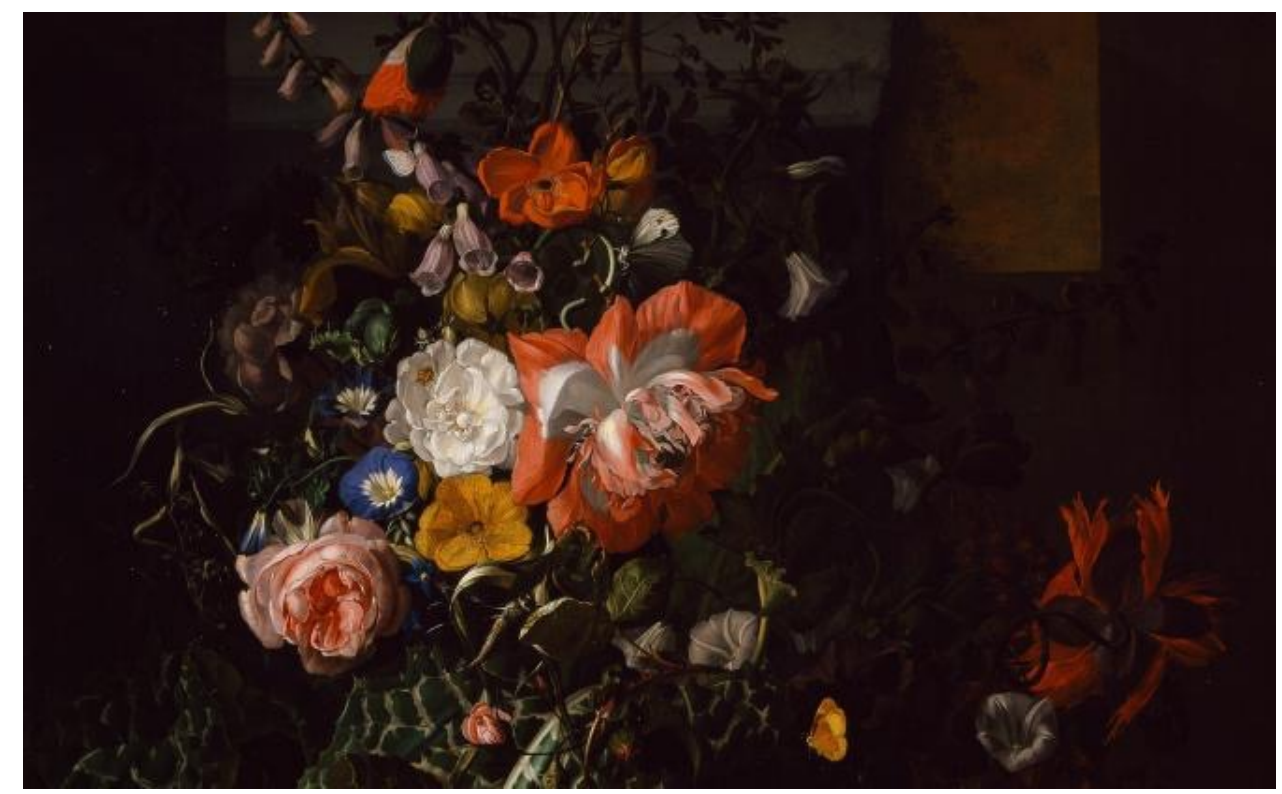

Fig. 10. Rachel Ruysch, Roses, Convolvulus, Poppies, and Other Flowers in an Urn on a Stone Ledge, c. 1860s, oil on canvas. 42" x 33". Accessed from https://nmwa.org/works/rosesconvolvulus-poppies-and-other-flowers-urn-stone-ledge (accessed April 18th, 2018).

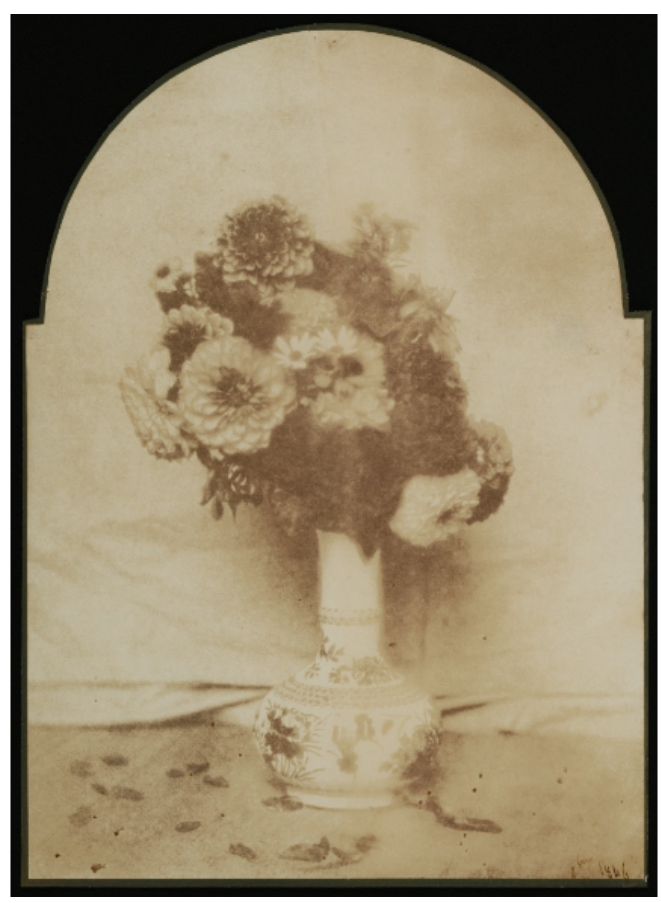

Fig. 11. Hippolyte Bayard, Still Life of Flowers in a Vase, 1846, salted paper print. 17 x $12.3 \mathrm{~cm}$. Accessed from http://www.getty.edu/art/collection/objects/102053/hippolyte-bayard-still-life-offlowers-in-a-vase-french-november-1846/ (accessed April 22nd, 2018). 


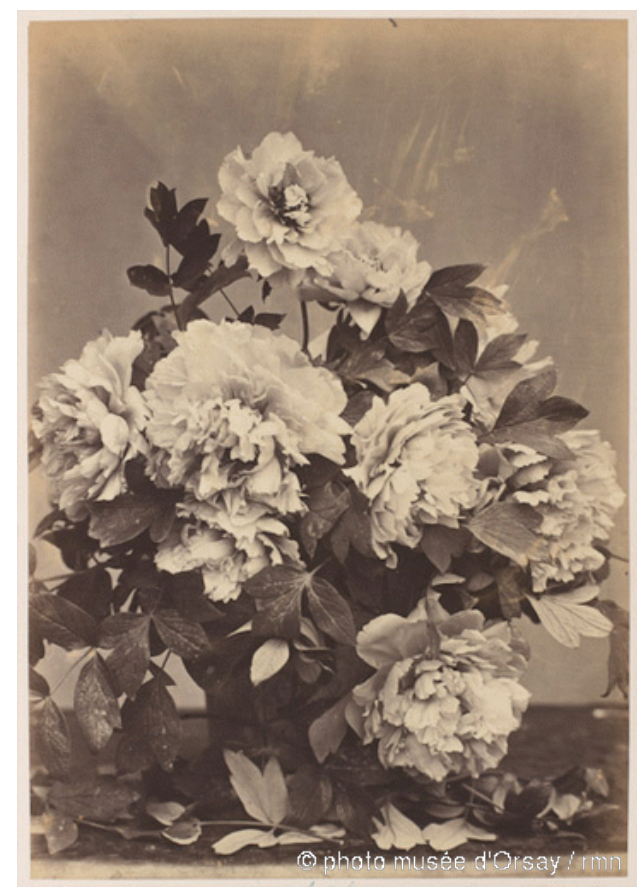

Fig. 12. Charles Aubry, Nine Peonies, c. 1864, albumen print. Reproduced from http://www.musee-orsay.fr/en/collections/index-ofworks/notice.html?no cache $=1 \&$ nnumid $=027635 \& \mathrm{cHash}=2 \mathrm{c} 254886 \mathrm{f0}$, (accessed April 22nd, 2018).

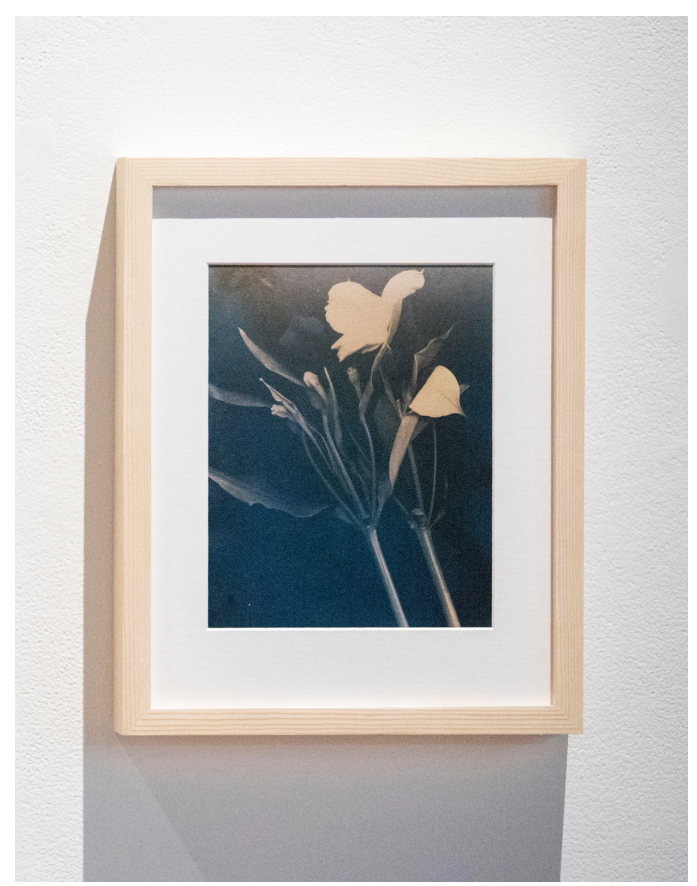

Fig. 13. Allison Semele Blair, What the Frost Killed: Bouquets (detail), 2018, toned cyanotype. (Photo courtesy of Michael Oliver). 


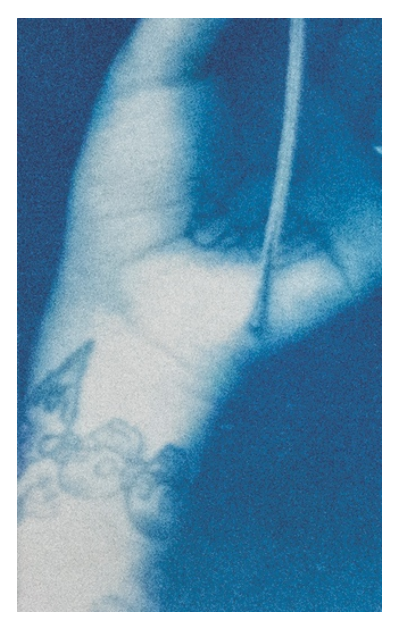

Fig. 14. Allison Semele Blair, What the Frost Killed: Bouquets (detail), 2018, cyanotype.
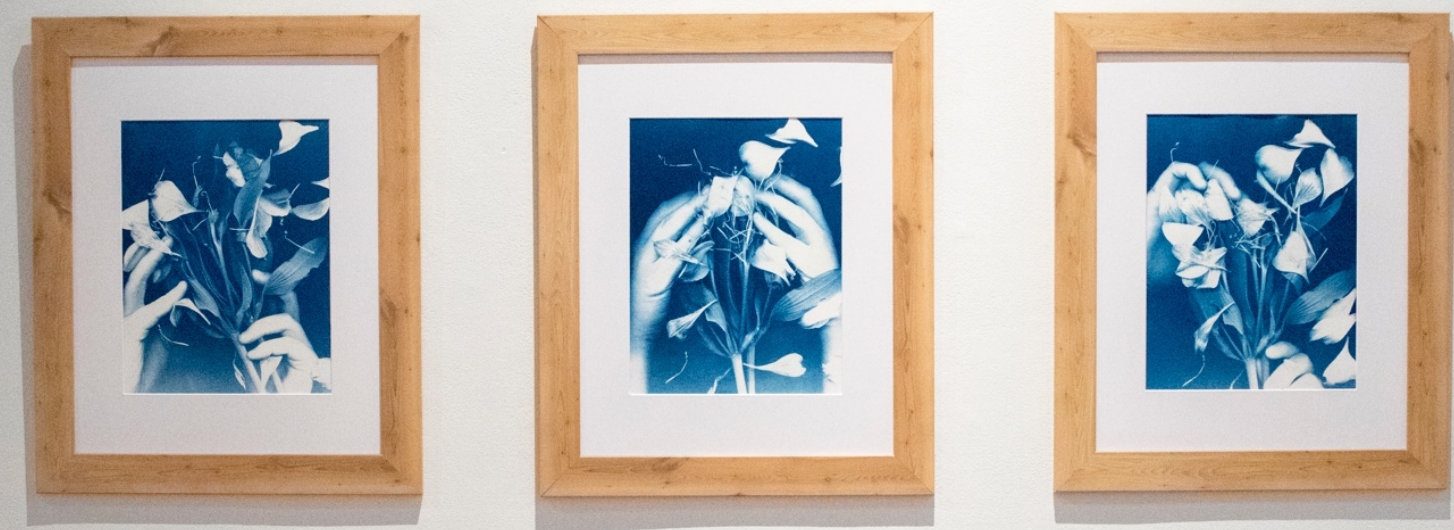

Fig. 15. Allison Semele Blair, Ilioupersis, 2018, cyanotypes. 


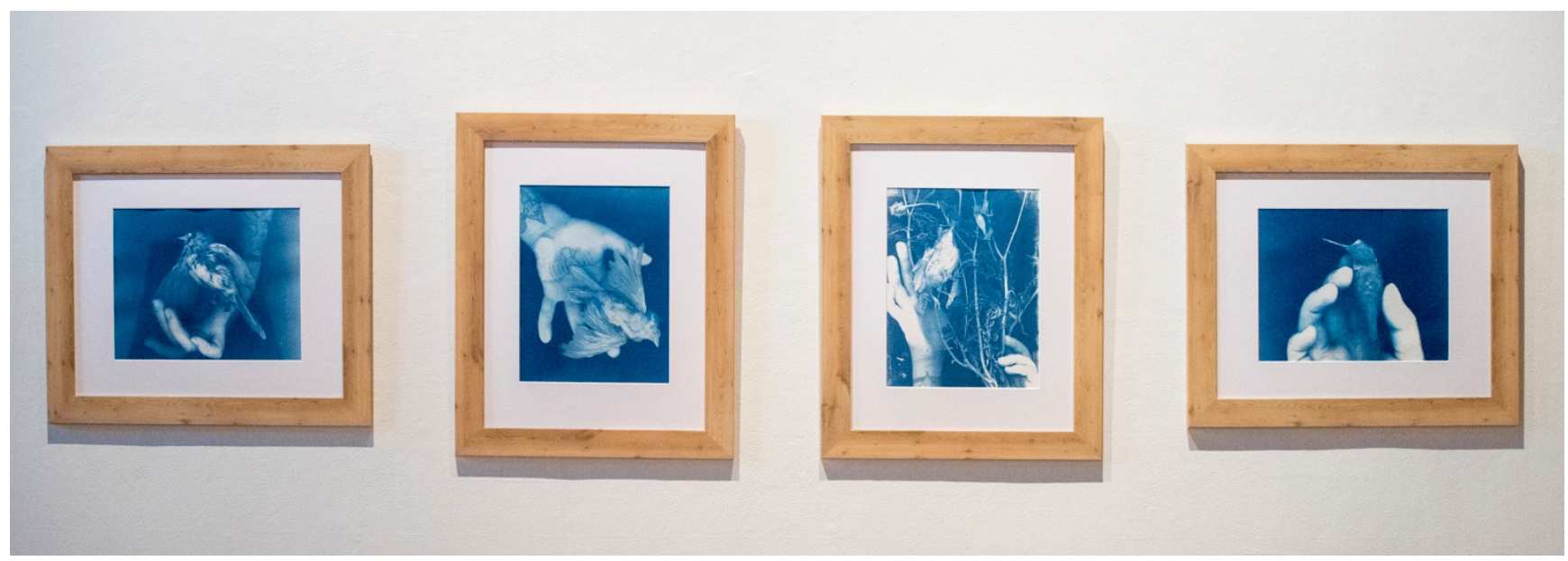

Fig. 16. Allison Semele Blair, Transferred Epithets, 2018, cyanotypes.

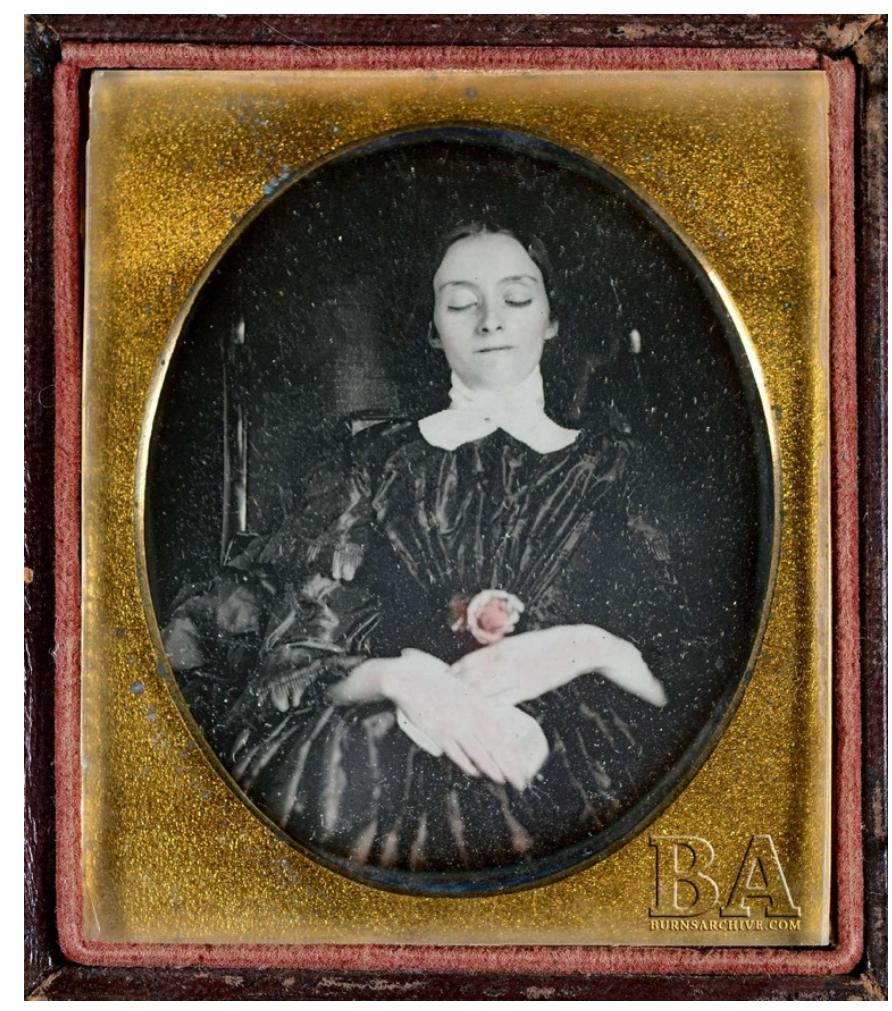

Fig. 17. Unknown Artist, Young Woman with Rose, c. 1844, tinted sixth-plate daguerreotype. Reproduced from https://folkartmuseum.org/exhibitions/securing-the-shadow-posthumousportraiture-in-america/ (accessed April 22 ${ }^{\text {nd }}, 2018$ ). 


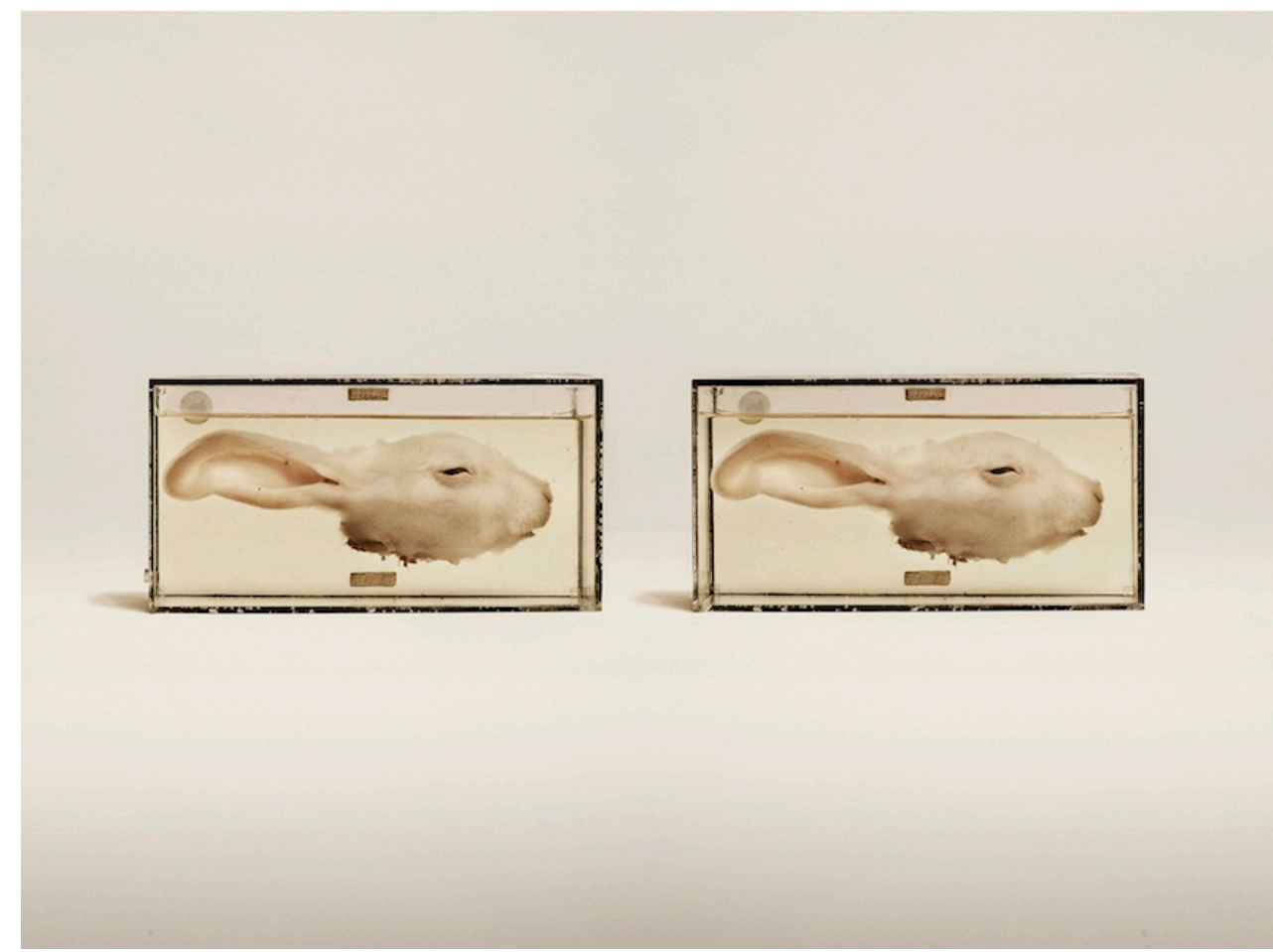

Fig. 18. Jim Naughten, Domestic Rabbit, 2014, stereoscopic photograph. Reproduced from https://hyperallergic.com/300647/the-relics-of-victorian-natural-history-in-eye-poppingstereoscope/ (accessed April 22 $\left.{ }^{\text {nd }}, 2018\right)$. 


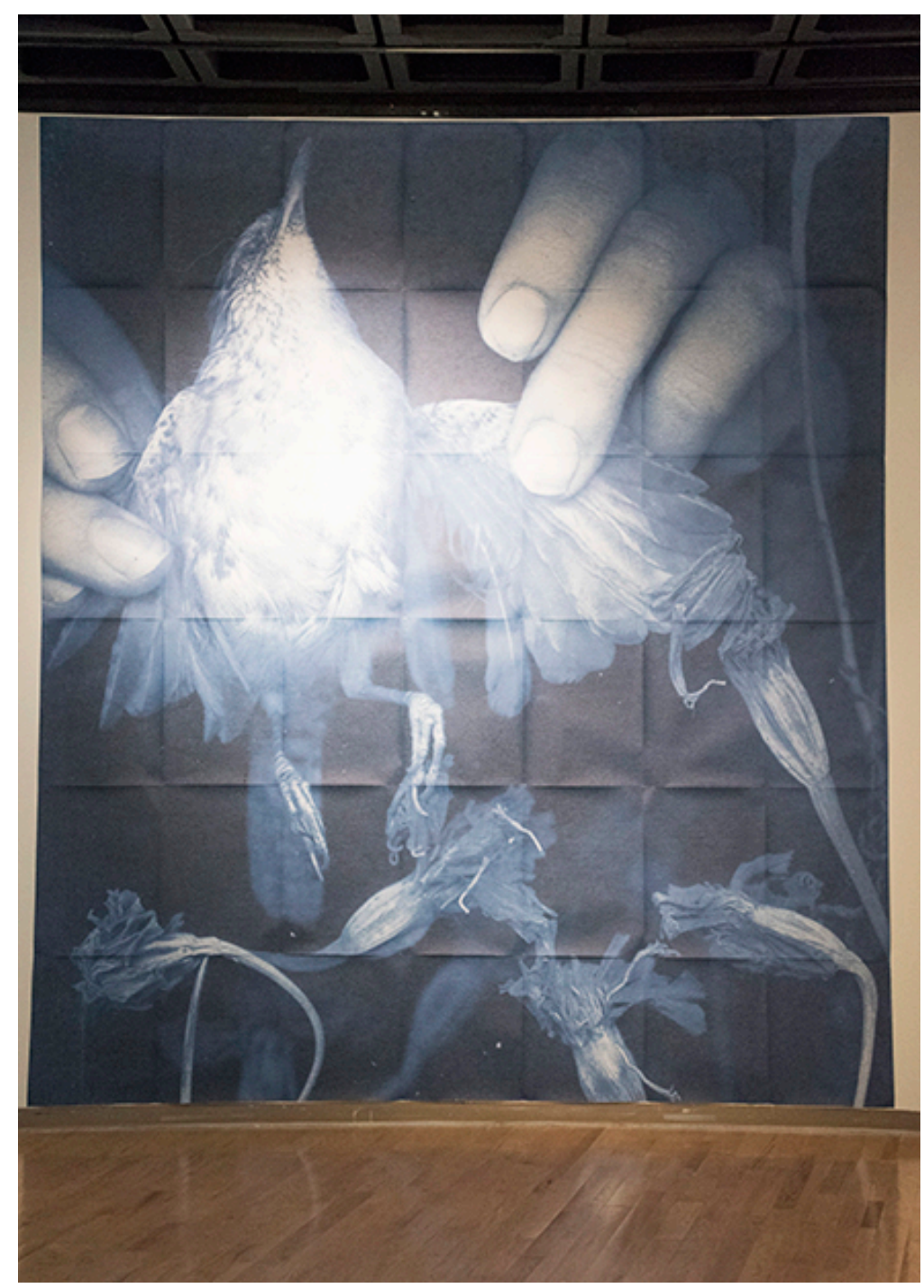

Fig. 19. Allison Semele Blair, Specter, 2018, inkjet reproduction of a cyanotype. (Photo courtesy of Michael Oliver). 


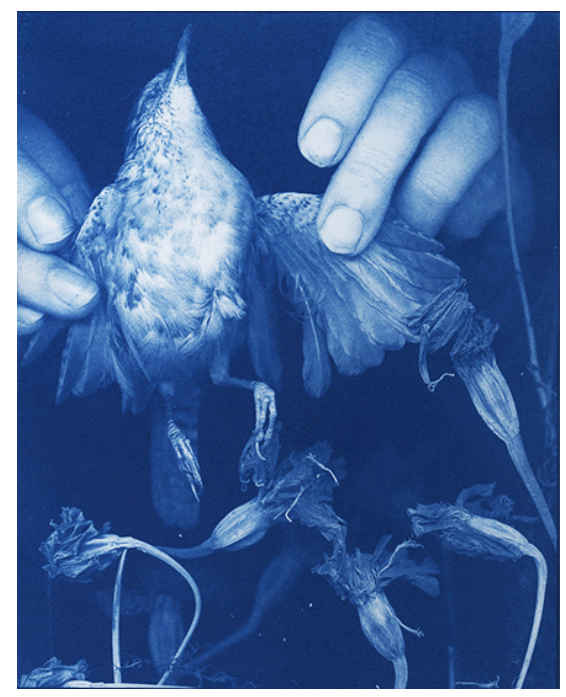

Fig. 20. Specter from Wooden Walls/Second Ships, 2016, cyanotype.

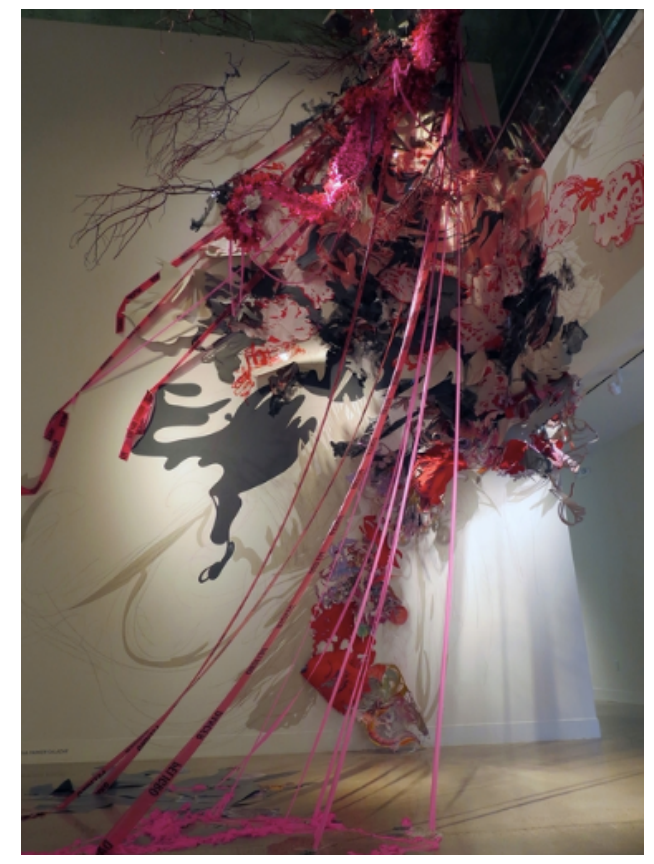

Fig. 21. Samantha Parker Salazar, Leukos-Haima v. 2, 2014, monotype, paint, drawing, digital on hand-cut paper, acetate, flagging tape, wood, monofilament. Reproduced from http://www.sparkersalazar.com/2015-1/8milbxojrc64p7ai8mklc6b6789pxc (accessed April 22nd, 2018). 


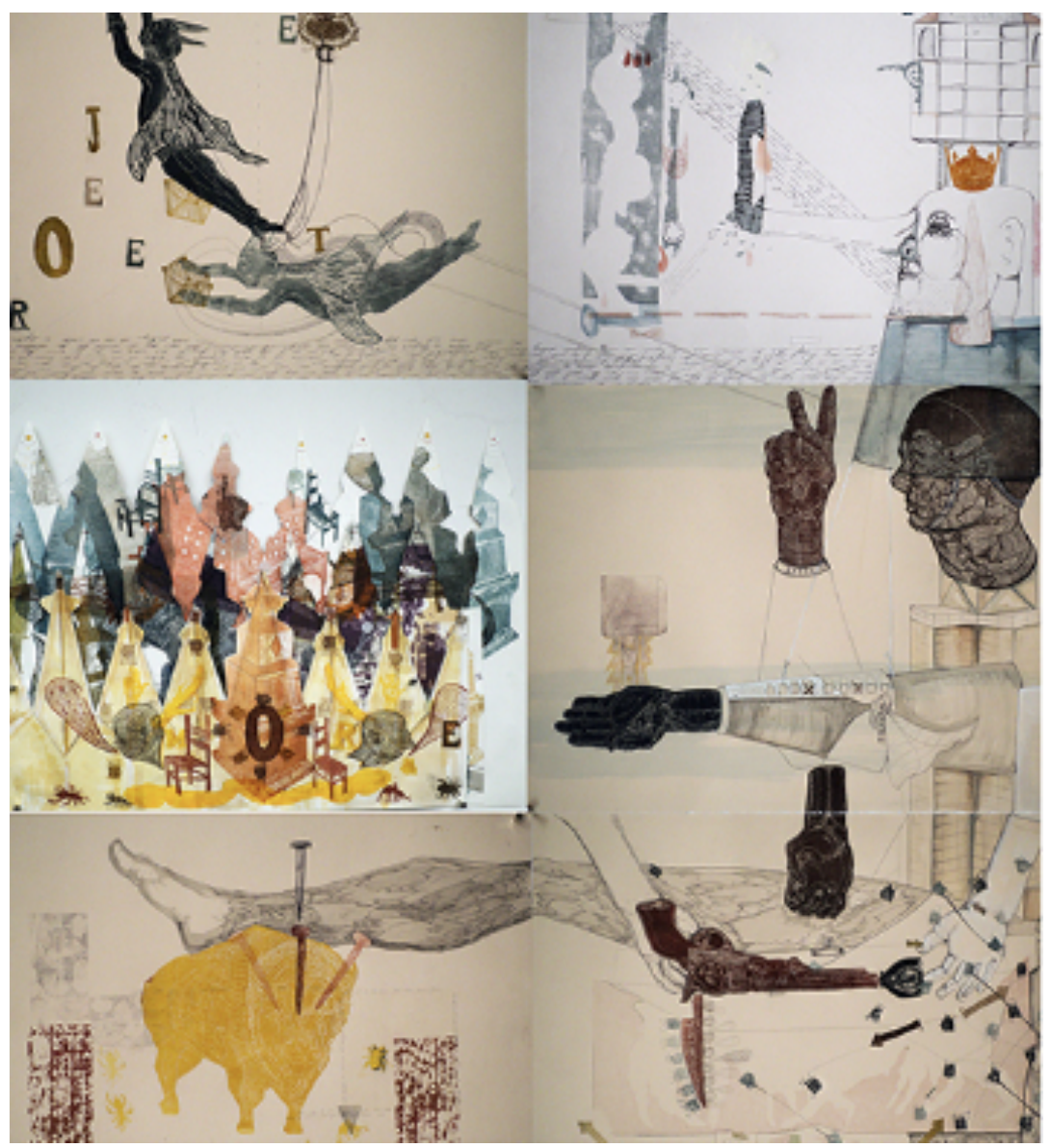

Fig. 22. Marty Azevedo, Building Steam (detail), 2013, relief, lithography and mixed media. Reproduced from http://www.marty-

azevedo.com/humannature/2016/4/9/building-steam-detail (accessed April 22 nd, 2018).

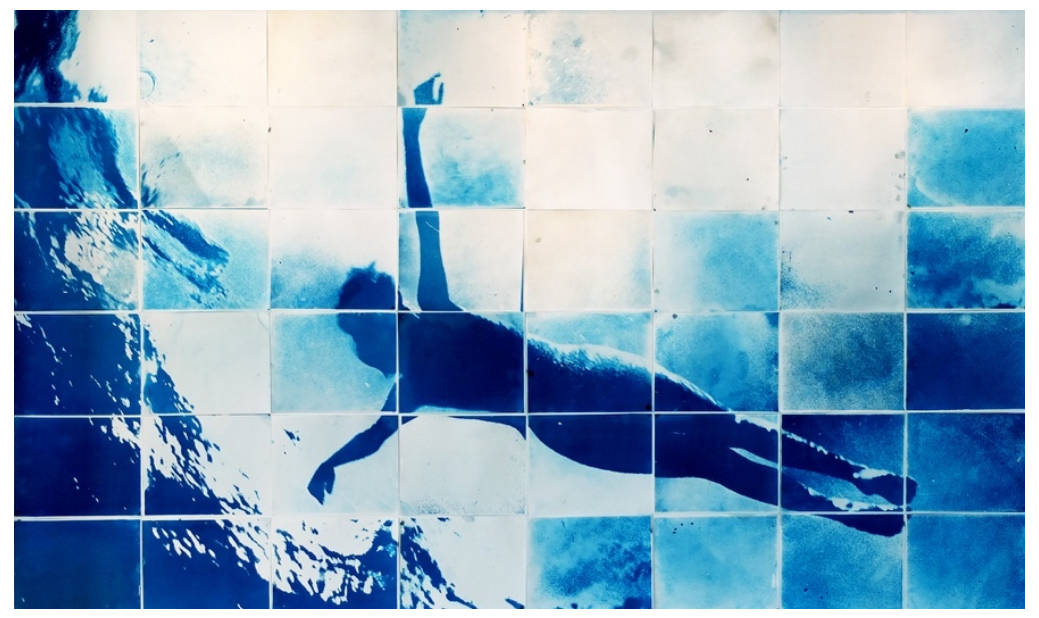

Fig. 23. Jeffrey Apoian, Float, 2014, mosaic cyanotype. Reproduced from http://www.prweb.com/releases/2014/09/prweb12140587.htm (accessed April 22nd, 2018). 


\section{Bibliography}

“AK47 vs. M16," The Propeller Group, 2015. Accessed April 2018. http://www.the-propeller-group.com/ak-47vsm16

Apoian, Jeffrey. "Artist APOIAN's Mosaic Cyanotype Exhibit, 'Float': An Aegean Odyssey." PRWeb, September 5th, 2014. Accessed April 2018.

Benjamin, Walter. "The Work of Art in the Mechanical Age of Reproduction," Illuminations, ed. Hannah Arendt, trans. Harry Zohn. New York: Schocken Books, 1969.

Dobb, Edwin. "Sun Gardens: Anna Atkins and Her Botanical Blueprints," The Sciences vol. 25, no. 6 (1985): 34-43.

Fer, Briony, David Batchelor, and Paul Wood. Realism, Rationalism, Surrealism: Art between the Wars. New Haven: Yale University Press, 1993.

de Font-Reaulx, Dominique. Painting and Photography, 1839-1914. Paris: Flammarion, 2012.

Kelsey, Robin. Photography and the Art of Chance. Cambridge: Harvard University Press: 2015

Loose, Ted. "Cyanotype, Photography's Blue Period, Is Making a Comeback," New York Times, Feb. 5, 2016.

Martindale, Charles. Redeeming the Text: Latin Poetry and the Hermeneutics of Reception. Cambridge: Cambridge University Press, 1993.

Martineau, Paul. Still Life in Photography. Los Angeles: J. Paul Getty Museum, 2010.

Meier, Allison. "Photographs of Birds and Bones in US National Park Collections," Hyperallergic, July 13th, 2016.

https://hyperallergic.com/304776/photographs-of-the-birds-and-bones-in-us-nationalpark-collections/

Meier, Allison. "The Relics of Victorian Natural History in Eye-Popping Stereoscope," Hyperallergic, May 24th, 2016.

https://hyperallergic.com/300647/the-relics-of-victorian-natural-history-in-eye-poppingstereoscope/

Newhall, Beaumont. The History of Photography. New York: Museum of Modern Art, 1982.

Pollitt, J.J.. Art and Experience in Classical Greece. New York: Cambridge University Press, 1972.

Rexer, Lyle. Photography's Antiquarian Avant-Garde: The New Wave in Old Processes. 
New York: Harry N. Abrams, Inc., 2002.

Voon, Claire. "Photography's Blue Period Gets Its First Major Show in the US." Hyperallergic, February 25, 2016. Accessed April 1, 2017. https://hyperallergic.com/272915 photographys-blue-period-gets-its-first-major-show-in-the-us/. 